\title{
Experimental Research and Simulation Analysis of Lightning Ablation Damage Characteristics of Megawatt Wind Turbine Blades
}

\author{
Yang Zhao ${ }^{1}$, Bin Yang ${ }^{2, *}$ and Yao Zhang ${ }^{3}$ \\ 1 Shanghai Center for Meteorological Disaster Prevention Technology, Shanghai 200030, China; \\ zhaoyang@lightning.sh.cn \\ 2 School of Aerospace Engineering and Applied Mechanics, Tongji University, Shanghai 200092, China \\ 3 School of Electrical Engineering, Shanghai University of Electric Power, Shanghai 200090, China; \\ zhangyao8253@163.com \\ * Correspondence: yangbin2018@tongji.edu.cn
}

Citation: Zhao, Y.; Yang, B.; Zhang, Y. Experimental Research and Simulation Analysis of Lightning Ablation Damage Characteristics of Megawatt Wind Turbine Blades. Metals 2021, 11, 1251. https:// doi.org/10.3390/met11081251

Academic Editors: Soran Birosca, Eric Hug and Frank Czerwinski

Received: 3 June 2021

Accepted: 3 August 2021

Published: 6 August 2021

Publisher's Note: MDPI stays neutral with regard to jurisdictional claims in published maps and institutional affiliations.

Copyright: (c) 2021 by the authors. Licensee MDPI, Basel, Switzerland. This article is an open access article distributed under the terms and conditions of the Creative Commons Attribution (CC BY) license (https:// creativecommons.org/licenses/by/ $4.0 /)$.

\begin{abstract}
In this paper, the damage mechanism of glass fiber reinforced composite (GFRC) under lightning strike by laying and inserting copper wires in the laminate was studied. The ablation characteristics of GFRC under different lightning current components were explored. Scanning electron microscope (SEM) was used to conduct the morphology analysis at the damaged area. The results show that the high temperature induced by lightning striking leads to resin pyrolysis, glass fiber (GF) sublimation, and stress waves, which results in fiber breakage and delamination. Then, a finite element (FE) thermal-electric coupling model for predicting the lightning ablation damage of GFRC was established. The comparison between the simulation and experimental results are in good agreement, which validate the effectiveness of the proposed FE model. The relationship between the lightning ablation area and the lightning current amplitude, charge amount, and specific energy in creeping discharge and through discharge was obtained by data fitting. The whole ablation damage process was revealed by FE simulation.
\end{abstract}

Keywords: glass fiber reinforced composite (GFRC); lightning strike; finite element (FE); thermalelectric coupling; ablation damage

\section{Introduction}

Fiber-reinforced composite (FRC) materials have been widely employed in aeronautics, astronautics, power industry, and other fields due to their light weight, high specific strength, high specific modulus, good corrosion resistance, and fatigue resistance [1-4]. In recent years, many countries, such as Germany, Denmark, Netherlands, United States, and China, are vigorously promoting the development of wind power industry for sustainable development and carbon neutral goals. As known, the application of FRC materials on wind turbine blades can effectively reduce energy consumption and improve power generation efficiency [5], so engineers have increasingly focused on the damage mechanism of FRC materials applied to wind turbine blades. Wind turbines are generally located in thunderstorm-intensive areas, such as seaside, sea, and plateau. Furthermore, the wind turbine is usually higher than the other adjacent objects. Hence, the wind turbine blades which have the highest position is most likely to be struck by lightning. The size of the blades and the height of the wind turbine continue to increase due to the increasing requirements for installed capacity, making this problem even more serious [6].

Lightning is a common discharge phenomenon in nature. The voltage and the current amplitude can be as high as $500 \mathrm{kV}$ and $200 \mathrm{kA}$, respectively. The duration of discharge is usually hundreds of microseconds. The discharge process is accompanied by strong shock waves, huge electromagnetic fields, strong electromagnetic radiation, and hot high temperatures $[7,8]$. The blades are mainly made of GFRC, which have high electrical 
insulation. Various damages including resin pyrolysis, fiber sublimation and laminate delamination can be detected when the blades are struck by lightning $[9,10]$. As known, it is very hard to immediately repair the damages in the GFRC caused by lightning strikes. Hence, the lightning induced damages may continue to propagate under external load or degrade, and eventually leading to the collapse of the wind turbine blades. A lot of research studies have been conducted on the lightning ablation and residual mechanical behavior of composite materials. It was reported that lightning striking damages greatly reduced its residual strength [11,12]. Garolera et al. [13] presented an analysis of lightning damage on wind turbine blades in the U.S. and found that the damage mainly occurred at the tip, and four main types of damage can be recognized including damaged blade skin surface, carbonization of blade, blade skin breakdown and fuse of the lead wire inside the blade. Hirano et al. [14] studied the damage evolution law of graphite/epoxy composites under lightning struck and summarized the damage as three types of damage: fiber damage, resin degradation, and internal delamination by using infrared, ultrasonic, and other detection methods.

Lightning strike damage of composite materials and their lightning protection are one of the hotspots in the field of the composite damage. However, although glass fiber composite materials are widely used in the manufacture of wind turbine blades, most research works still focus on the damage characteristics analysis of carbon fiber composite materials under lightning striking, and mainly detected the macroscopic damage [15-18]. Guo et al. [19] conducted a series of lightning striking test on the blades in a rotating state and reveals the lightning damage mechanism of blade. The results offer an intuitive impression of the blade lightning process to engineers and promotes the development of wind turbine lightning protection technology. However, the lightning strike problems in the actual operation of the blades are complex and diverse. The existing research is still not comprehensive, especially the research on the characteristics and mechanism of ablation damage of wind turbine blades under multi-component lightning striking. However, the previous study did not consider the lightning ablation damage of wind turbine blade under creeping discharge, which is also a very common discharge form induced by lightning striking. Therefore, it is necessary to carry out more in-depth research on the lightning ablation damage of GFRC under creeping discharge.

This work proposed a method of laying and inserting copper wires to conduct ablation damage tests of GFRC laminates under multi-component lightning striking and discussed the effects of different components on the ablation characteristics of GFRC. Meanwhile, an FE thermal-electric coupling model for predicting the lightning ablation damage of GFRC was established, which have been validated by comparing with the test results. Finally, the function relationship between ablation damage area and lightning current amplitude, charge amount and specific energy is established, which provides a theoretical basis for the study on the lightning damage of GFRC used in wind turbine blades.

\section{Materials and Methods}

\subsection{Materials}

GFRC laminate used in the experiment has a size of $150 \mathrm{~mm} \times 100 \mathrm{~mm}$ in length and width, which is made of ETL 1215 EP triaxial GF cloth and 2511-1A/1BS epoxy resin as shown in Figure 1. The cured GFRC panels had a nominal thickness of $1 \mathrm{~mm}, 2 \mathrm{~mm}$, and $4 \mathrm{~mm}$, and the corresponding stacking sequence are $\left[0^{\circ}\right],\left[0^{\circ} / 90^{\circ}\right]$, and $\left[0^{\circ} / 45^{\circ} /-45^{\circ} / 90^{\circ}\right]$. 


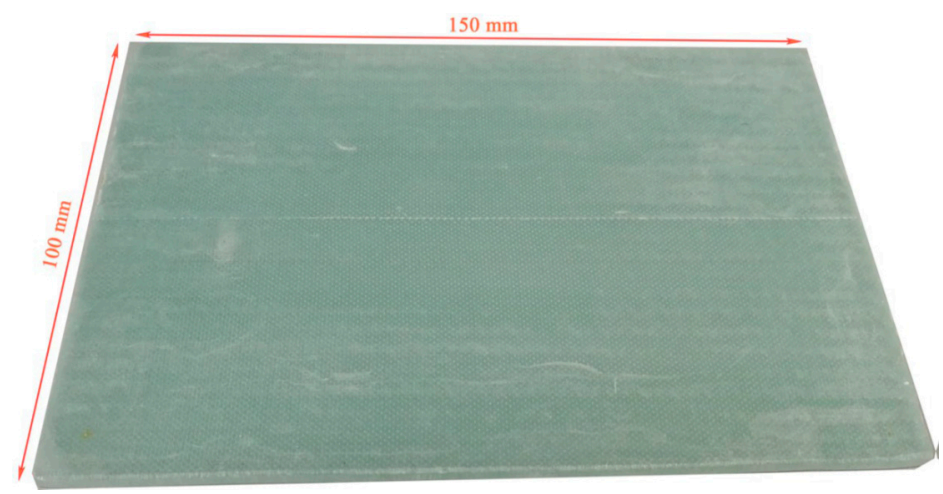

Figure 1. The GFRC material laminate.

\subsection{Test Equipment}

In this experiment, an impulse current generator and a multi-waveform lightning current generator are used to simulate different lightning current components. Figure $2 \mathrm{a}$ shows the Haefely SSGA 200-180 Impulse Current Generator (ICG) (Haefely, Basel, Switzerland), which can output the first return stroke component having an equivalent energy with the lightning current component $\mathrm{A}$, and the maximum transferred charge Qs $=50 \mathrm{As}$ and the maximum specific energy $\mathrm{W} / \mathrm{R}=3 \times 10^{3} \mathrm{KJ} / \Omega$. The waveform of lightning current component A generated by Haefely SSGA 200-180 ICG is shown in Figure 3a.

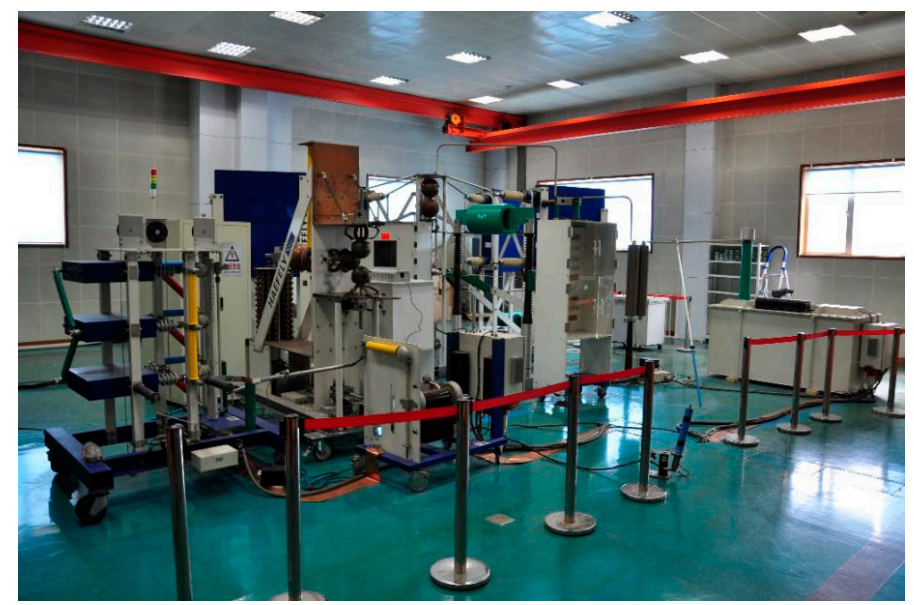

(a) Haefely SSGA 200-180 Impulse current generator

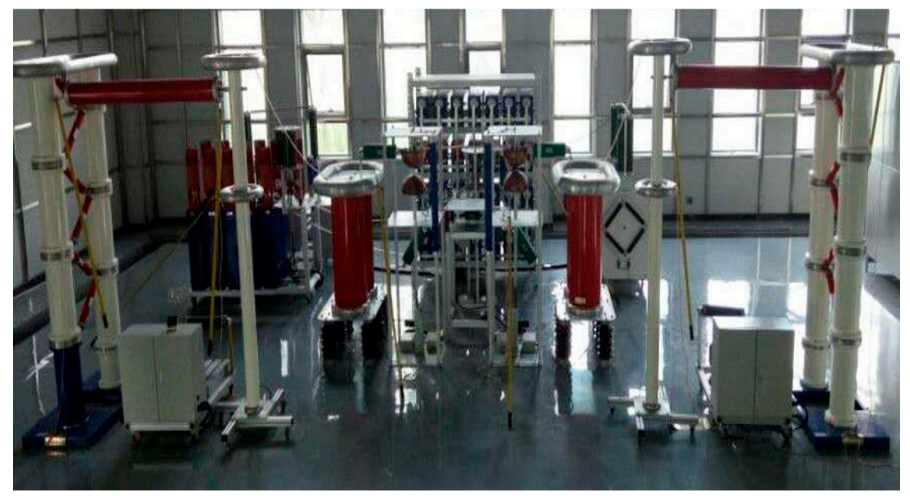

(b) Multi-waveform lightning current generator

Figure 2. Artificial lightning current experiment.

Figure $2 b$ shows the multi-waveform lightning current generator, which can output two lightning current components. As shown in Figure 3b, the duration of the lightning 
current component $B$ is about $2 \mathrm{~ms}$, and the current amplitude is $2-8 \mathrm{kA}$. As shown in Figure $3 c$, the duration of the lightning current component $C$ is nearly $2 \mathrm{~s}$, and the current amplitude is $100-800 \mathrm{~A}$.

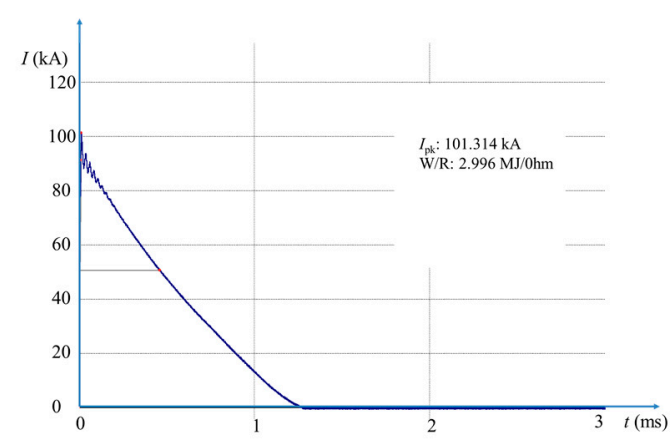

(a)

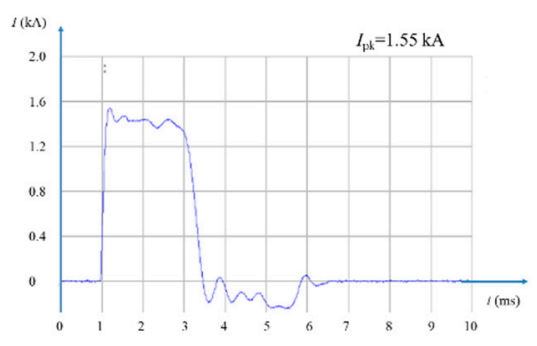

(b)

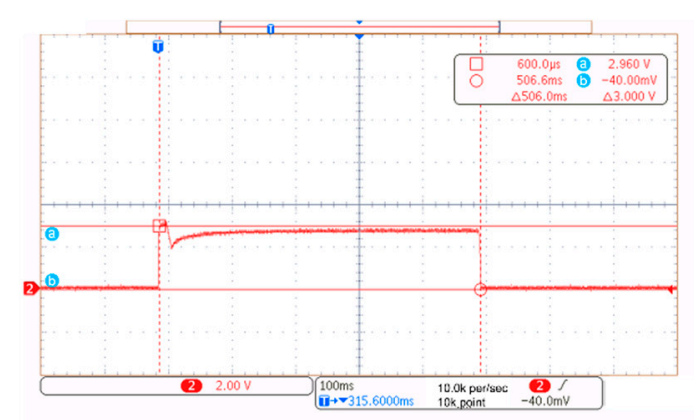

(c)

Figure 3. Three components of lightning current, (a) lightning current component $\mathrm{A}$, (b) lightning current component $B,(c)$ Lightning current component $C$.

\subsection{Test Setup}

The GFRC laminate was clamped in an insulating jig. A copper wire with a diameter of $0.4 \mathrm{~mm}$ was inserted on the upper surface of the GFRC as an ignition channel, which was arranged from the center of the laminate to the grounding copper bar. The length of the copper wire is $75 \mathrm{~mm}$. In addition, a cylindrical tungsten-copper alloy rod with a length of $5 \mathrm{~mm}$ and a radius of $3 \mathrm{~mm}$ was used as the discharge electrode. The electrode was perpendicular to the test sample and had a $2 \mathrm{~mm}$ discharge distance.

Lightning current has two characteristics: high voltage and high current. However, in the high voltage laboratory, the voltage of impulse current generated by the impulse current generator (ICG) is not enough to break down the GFRC. Therefore, a copper wire was layered or inserted in the GFRC as a lightning channel to attract artificial lightning and enhance its dielectric breakdown capacity. As shown in Figure 4, the impulse current punctures the gap between the discharge electrode and the copper wire and connects to the grounding copper bar to form a current loop. Then, the ablation damage mechanism of the GFRC laminate under lightning striking can be analyzed experimentally. 


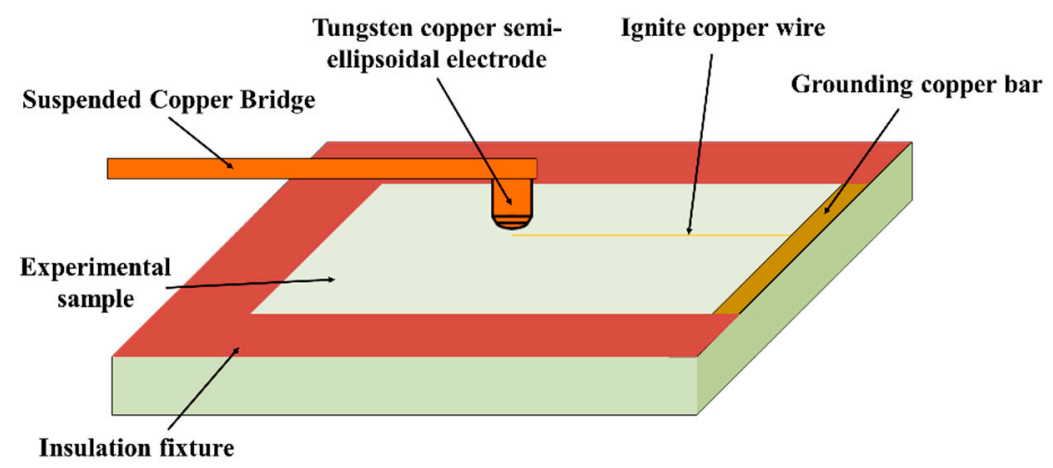

Figure 4. Schematic diagram of GFRC material along the surface ablation experiment layout.

A pilot copper wire with a diameter of $0.4 \mathrm{~mm}$ was inserted vertically in the middle of the GFRC laminate. The length of the copper wire above the surface layer was $15 \mathrm{~mm}$, and the distance between the discharge electrode and pilot copper wire was $2 \mathrm{~mm}$. The grounding copper bar is placed below the test sample to form a current loop (see Figure 5).

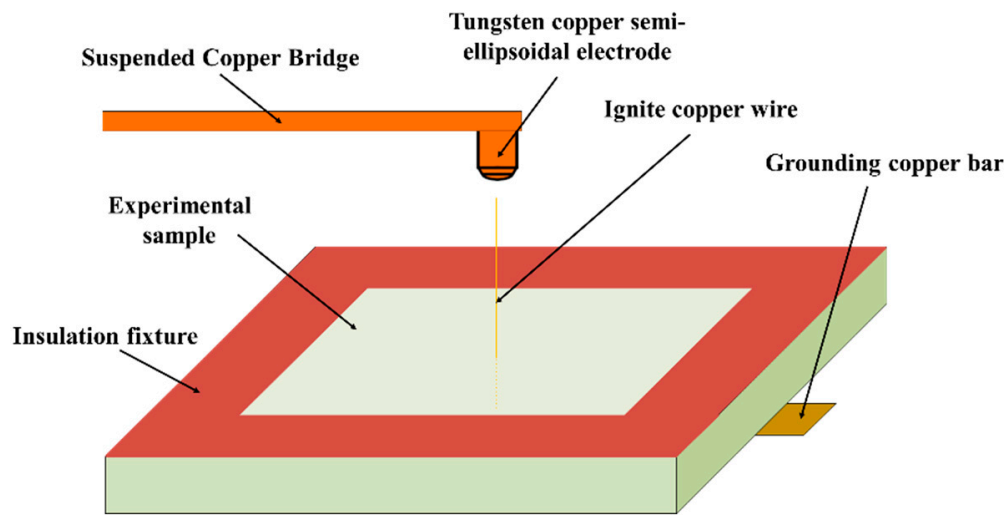

Figure 5. Schematic diagram of GFRC penetration ablation experiment layout.

\section{Simulation on Lightning Ablation Damage}

\subsection{Basic Theory}

An FE thermal-electric coupling model is proposed to simulate the lightning ablation damage of GFRC used for wind turbine blade. In terms of the lightning striking damage process of GFRC, the lightning current flows from the high-potential to the low-potential, forming an arc channel and converting electrical energy into Joule heat. As known, current conduction and heat transfer are interdependent, that is, electrical conductivity is related to temperature and Joule heating is related to the current density. Hence, the electrical conduction and heat transfer can be coupled together completely, and the potential gradient and temperature distributed at each node can be calculated simultaneously.

\subsubsection{Electric Field Formula}

The electrical field in a conducting material is governed by Maxwell's equation:

$$
\int_{\mathrm{S}} J \cdot n d S=\int_{v} r_{c} d V
$$

where $S$ is the cell cross-sectional area, $V$ denotes any control volume of the surface $S, n$ is the outer normal direction vector of the surface $S, J$ is the current density (current per unit area), and $r_{c}$ is the internal volumetric current source per unit volume.

Converting area integral to volume integral using the divergence theorem:

$$
\int_{\mathrm{s}}\left(\nabla \cdot J-r_{c}\right) d V=0
$$


Since the volume is arbitrary, the differential equation is written as:

$$
\nabla \cdot J-r_{c}=0
$$

Introducing any variable potential field $\delta \phi$, and integrating over the whole volume, the variational form is given as:

$$
\int_{v} \delta \phi\left(\nabla \cdot J-r_{c}\right) d V=0
$$

Rewritten as:

$$
-\int_{V} \nabla \delta \phi \cdot J d V=\int_{S} \delta \phi \bar{J} d S+\int_{V} \delta \phi r_{c} d V
$$

where $\bar{J}$ is the current intensity $\bar{J}=J \cdot n$ flowing to the control body $V$ and $\phi$ is the potential energy.

The flow of electrical current is described by Ohm's law:

$$
J=\sigma \cdot E=-\sigma \cdot \nabla \phi
$$

where $\sigma, E$, and $\varphi$ denote the electric conductivity, the electrical field intensity, and electrical potential, respectively. The governing equation of finite element model is obtained by using Equation (6) in the conservation equation:

$$
\int \nabla \delta \phi \cdot(\sigma \cdot \nabla \phi) d V=\int_{V} \delta \phi r_{c} d V+\int_{S} \delta \phi \bar{J} d S
$$

In this equation, $\bar{J}(\bar{J}=-J \cdot n)$ is electrical current density entering the control volume across $S$. Joule's law describes the rate of electrical energy, $P_{e c}$, dissipated by current flowing through a conductor as:

$$
\begin{gathered}
P_{e c}=J \cdot E=(\sigma \cdot E) \cdot E \\
r=\eta_{v} P_{e c}
\end{gathered}
$$

\subsubsection{Thermal Balance}

The heat conduction behavior is described by the basic energy balance relation:

$$
\int_{v} \rho C_{v} \frac{\partial \theta}{\partial t} \partial \theta d V+\int_{v} \nabla \partial \theta \cdot(K \cdot \nabla \theta) d V=\int_{v} \delta \theta r d V+\int_{S} \delta \theta q d S
$$

where $V$ is a volume of solid material, with surface area $S, \theta$ is the temperature, $K$ is the thermal conductivity matrix, $\rho$ is the material density, $C_{v}$ is the specific heat capacity, and $q$ is the heat flux density of the control body $V$.

Then, the temperature-related conductivity is derived as: $\sigma=\sigma(\theta)$; the heat generation density related to the current density: $r=r(J)$. Finally, the potential, current, temperature, and Joule heat at each node of the GFRC laminate under lightning striking can be calculated by the thermal-electric coupling equation.

\subsection{Surface Ablation Damage Modelling}

The FE model is constructed using the commercial software ABAQUS 6.14 (Dassault Systèmes Simulia Corp., Johnston, RI, USA), as shown in Figure 4. The model is 4-ply quasi-isotropic $\left[0^{\circ} / 45^{\circ} /-45^{\circ} / 90^{\circ}\right]$ type. The size of the GFRC laminate is determined by ASTM D7173 (SACMA SRM2) standard [20], so the length and width of the specimen are $150 \mathrm{~mm}$ and $100 \mathrm{~mm}$, respectively. The total panel thickness is $4 \mathrm{~mm}$, namely the thickness of each ply is $1 \mathrm{~mm}$. In the FE model, each layer of the laminate is divided by using an 8-node linear coupled thermal-electrical brick element type. The 22,050 solid elements (DC3D8E) are used to simulate the electrical-thermal propagation. 
The material is glass fiber/epoxy composite. The basic parameters such as density, expansion rate, thermal conductivity, specific heat capacity, electrical conductivity, and latent heat are listed in Table 1 [21].

Table 1. Physical properties of GFRC materials.

\begin{tabular}{|c|c|c|c|c|c|c|c|c|}
\hline \multirow{2}{*}{${ }^{\text {Temperature/ }}$} & \multirow{2}{*}{$\begin{array}{l}\text { Density/ } \\
\left(\mathrm{kg} / \mathrm{mm}^{3}\right)\end{array}$} & \multirow{2}{*}{$\begin{array}{c}\text { Specific Heat } \\
\text { Capacity/ } \\
\left(\mathrm{J} \cdot \mathrm{kg}^{-1} \mathrm{C}\right)\end{array}$} & \multicolumn{3}{|c|}{ Thermal Conductivity $/\left(\mathrm{W} \cdot \mathrm{m}^{-1} \cdot{ }^{\circ} \mathrm{C}\right)$} & \multicolumn{3}{|c|}{ Electricity Conductivity $/(\Omega \cdot \mathrm{mm})^{-1}$} \\
\hline & & & $\begin{array}{l}\text { Longitudinal } \\
\text { Direction }\end{array}$ & $\begin{array}{l}\text { In-Depth } \\
\text { Direction }\end{array}$ & $\begin{array}{l}\text { Transverse } \\
\text { Direction }\end{array}$ & $\begin{array}{l}\text { Longitudinal } \\
\text { Direction }\end{array}$ & $\begin{array}{l}\text { In-Depth } \\
\text { Direction }\end{array}$ & $\begin{array}{c}\text { Transverse } \\
\text { Direction }\end{array}$ \\
\hline 25 & 1200 & 956.3784 & 0.7761 & 0.2663 & 0.2661 & $1 \times 10^{-8}$ & $1 \times 10^{-9}$ & $1 \times 10^{-9}$ \\
\hline 300 & 1200 & 967.2042 & 0.7795 & 0.2792 & 0.2801 & $1 \times 10^{-8}$ & $1 \times 10^{-9}$ & $1 \times 10^{-9}$ \\
\hline 600 & 1200 & 1106.803 & 0.8122 & 0.3939 & 0.393 & $1 \times 10^{-6}$ & $1 \times 10^{-6}$ & $1 \times 10^{-6}$ \\
\hline 900 & 1200 & 1174.09 & 0.85 & 0.5125 & 0.5104 & $1 \times 10^{-6}$ & $1 \times 10^{-6}$ & $1 \times 10^{-6}$ \\
\hline 1100 & 1200 & 1174.09 & 0.8539 & 0.5135 & 0.5117 & $1 \times 10^{-6}$ & $1 \times 10^{-6}$ & $1 \times 10^{-6}$ \\
\hline$>1100$ & 1200 & 1174.09 & 1 & 1 & 1 & $1 \times 10^{-6}$ & $1 \times 10^{-6}$ & $1 \times 10^{-6}$ \\
\hline
\end{tabular}

A $75 \mathrm{~mm}$ long copper wire is set from the center to the right edge of the laminate to simulate the arc channel, as depicted in Figure 6. The boundary and loading conditions of the FE simulation model is consistent with that used in test conditions. The boundary conditions applied in the simulation are referred to the reference [16]. The right side of the specimen is electrically grounded, and the electrical potential is considered as zero. Thermal radiation is defined for the upper and side surfaces, whereas the bottom surface is assumed adiabatic since the temperature increment in the bottom surface can be neglected. The ambient temperature and thermal emissivity were set to $25{ }^{\circ} \mathrm{C}$ and 0.85 , respectively. Since the duration of lightning current acting on the laminate is on order of microseconds, the heat convection around the laminate is not considered. The attachment point is set on the center of the top layer, where a concentrated current load acts on (see Figure 3).

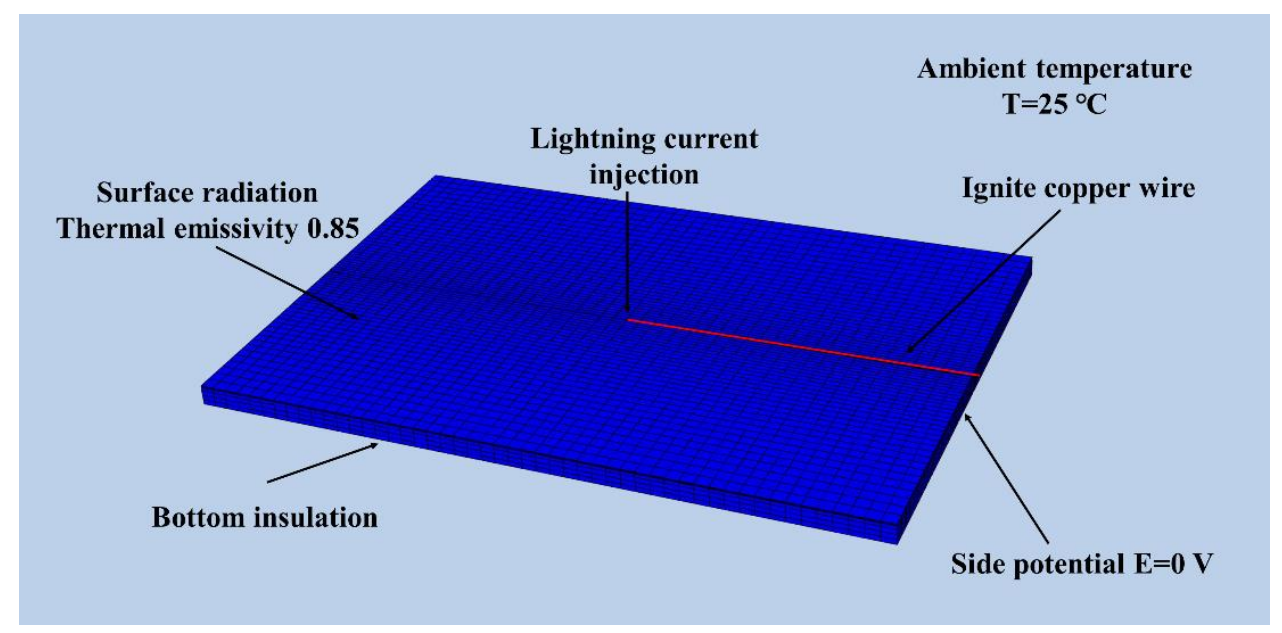

Figure 6. Lightning current loading diagram and boundary conditions along the surface of GFRC laminates.

During a lightning strike, the physical properties of GFRC materials (thermal conductivity, electrical conductivity, specific heat, etc.) will degrade as the temperature increases. Therefore, the subroutines HEAVEL and USDFLD were developed in the proposed FE simulation model to simulate the transient changes in the physical properties of GFRC laminates. The subroutine HEAVEL was used to determine the pyrolysis degree of epoxy resin. Figure 7 shows the specific analysis process of the lightning striking damage. It is defined that the epoxy resin starts to pyrolysis at $300^{\circ} \mathrm{C}$, completely decomposed at $600^{\circ} \mathrm{C}$, and eventually forms residual carbon. The sublimation temperature of GF is about $1100{ }^{\circ} \mathrm{C}$. The temperature of the node stops rising when the temperature reaches $1100{ }^{\circ} \mathrm{C}$. GF begins to soften at $830-860{ }^{\circ} \mathrm{C}$ and sublimate at around $1100^{\circ} \mathrm{C}$. The subroutine USDFLD was used to update the physical properties of the material based on the pyrolysis degree ob- 
tained by HEAVEL. Only component A waveform was selected for the simulation. Current amplitudes are in the range from $10 \mathrm{kA}$ to $100 \mathrm{kA}$.

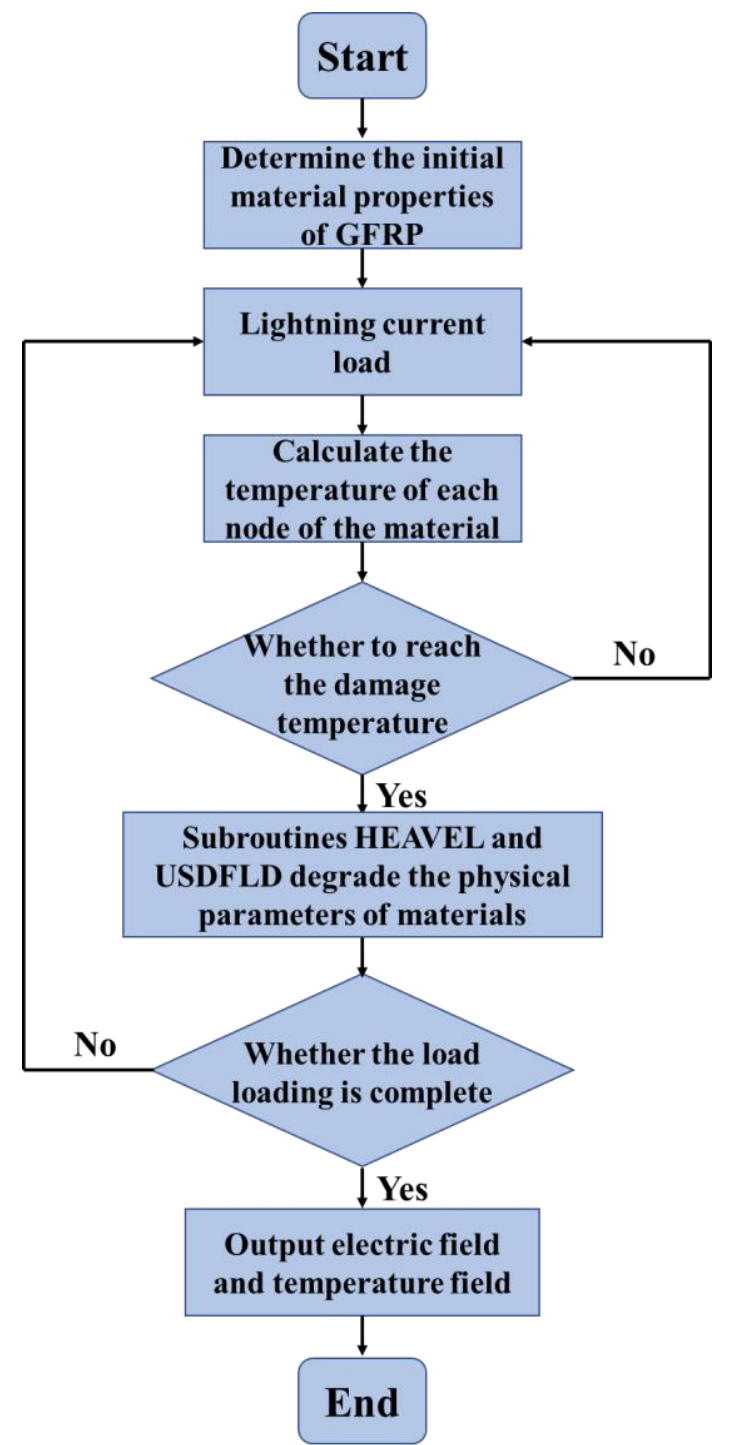

Figure 7. Electro-thermal coupling analysis flow chart.

\subsection{Through-Thickness Ablation Damage Modelling}

For the through-thickness ablation damage modelling (see Figure 8), the main failure mode of the GFRC laminate under lightning striking is through-thickness ablation damage. In generally, the resin pyrolysis and GF sublimates near the lightning attachment point will appear due to the high temperature of thousands to tens of thousands of Celsius degrees induced by lightning strikes. Furthermore, a large amount of pyrolysis gas is generated, which leads to the local blast and delamination [22]. It is known that the lightning current component $C$ transfers a large amount of electric charge, so it usually causes the most serious ablation damage. Table 2 describes the charge $Q_{s}$ and specific energy $\mathrm{W} / \mathrm{R}$ under the different lightning current component $C$ with a duration of $0.5 \mathrm{~s}$. 


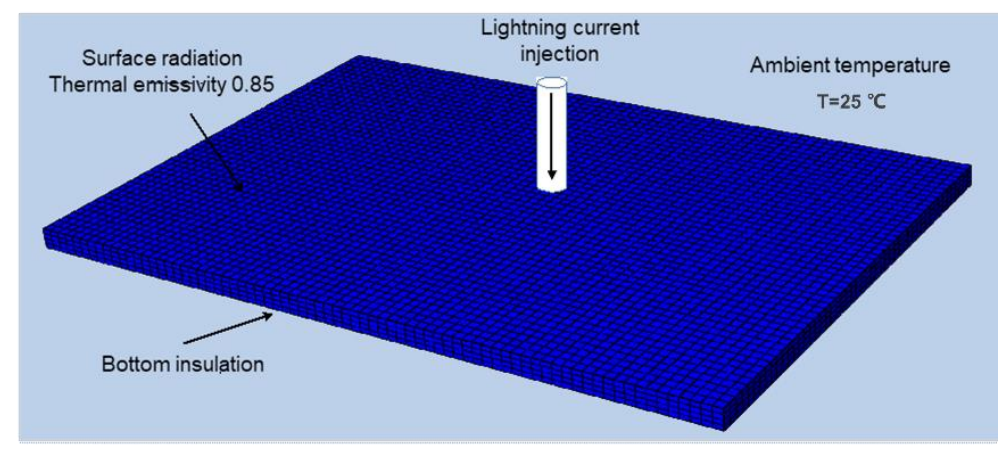

Figure 8. Loading and boundary conditions of through-thickness ablation damage modelling.

Table 2. Simulation experiment lightning current $C$ component parameter.

\begin{tabular}{ccc}
\hline $\boldsymbol{I}_{\mathbf{i m p}}(\mathbf{A})$ & $\mathbf{Q}_{\mathbf{S}}(\mathbf{A s})$ & Specific Energy W/R (kJ/ $\mathbf{)})$ \\
\hline 150 & 75 & 5.625 \\
200 & 100 & 10 \\
250 & 125 & 15.625 \\
300 & 150 & 22.5 \\
350 & 175 & 30.625 \\
400 & 200 & 40 \\
500 & 250 & 62.5 \\
600 & 300 & 90 \\
700 & 350 & 122.5 \\
800 & 400 & 160 \\
\hline
\end{tabular}

The lightning current cannot quickly discharge around the laminate through a conductor when it hits the GFRC vertically, due to its low conductivity and laminated characteristics. Since lightning current load applied to the surface of the laminate can be equivalent to the heat flux, so the heat flux was injected into the coupling model, and the functional relationship between the heat flux and the lightning current was obtained [23]. The detailed theoretical derivation is as follows:

$$
\begin{gathered}
r_{\text {arc }}=0.097[I(\mathrm{t})]^{\frac{1}{3}} t^{\frac{1}{2}} \\
Q_{\max } \approx 10 J=\frac{10 I(\mathrm{t})}{\pi\left[r_{\operatorname{arc}}(\mathrm{t})\right]^{2}} \\
Q(r)=Q_{\max } e^{-c_{0} r^{2}} \\
Q(r, \mathrm{t})=\frac{10 I(\mathrm{t})}{\pi\left[r_{\operatorname{arc}}(\mathrm{t})\right]^{2}} e \frac{\ln (0.1)}{r_{\operatorname{arc}}{ }^{2}(\mathrm{t})} r^{2}, r \leq r_{\operatorname{arc}}(\mathrm{t}) \\
\bar{Q}(\mathrm{t})=\frac{10 I(\mathrm{t})}{\pi\left[r_{\operatorname{arc}}(\mathrm{t})\right]^{2}} \frac{\int e \frac{\ln (0.1)}{r_{\operatorname{arc}}{ }^{2}(\mathrm{t})} r^{2} d r}{r_{\operatorname{arc}}(\mathrm{t})}
\end{gathered}
$$

where $r_{\text {arc }}$ is the arc radius (unit: $\mathrm{mm}$ ), $Q$ is the arc heat flux (unit: $\mathrm{W} / \mathrm{m}^{2}$ ), $J$ is the current density (unit: $\mathrm{A} / \mathrm{m}^{2}$ ), and $c_{0}$ is the distribution parameter.

\section{Results and Discussion}

\subsection{Experimental Analysis}

4.1.1. Ablative Damages along the Surface Direction

The three lightning current components A, B, and C were used to conduct creeping discharge experiments on the GFRCs. It can be found from Figure 9 obvious ablation damage and carbon grays due to epoxy resin pyrolysis occurs on the surface of the GFRC laminate under current component $\mathrm{A}$. The ablation damage of the GFRC laminate under 
current component B appears near the initial attachment point. Furthermore, there is no obvious GF breakages and epoxy resin pyrolysis along the discharge path, indicating that the component B has a little effect on the lightning striking damage of GFRCs. The lightning current only causes slight damage at the attachment point and discharges path under lightning current component $C$, and no visible delamination occurs. In addition, it was observed that the ignited copper wire is scattered on the surface of the laminate after the sublimation. The damage degree is much smaller than that under current component A. Therefore, the lightning current component $\mathrm{A}$ is the major factor that causing the lightning striking damages.

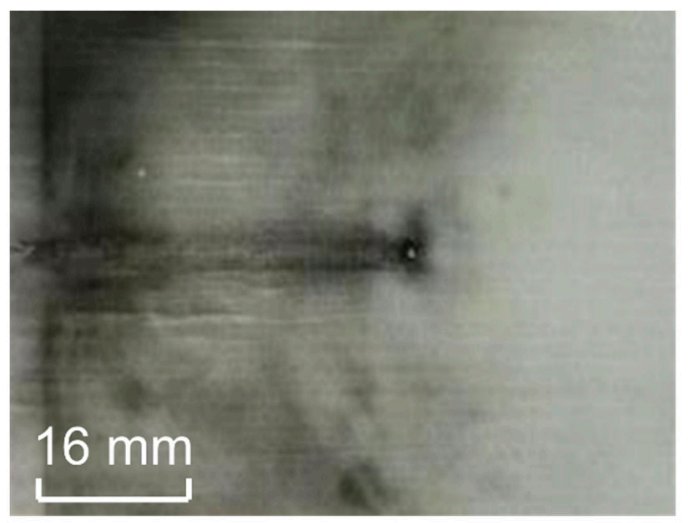

(a)

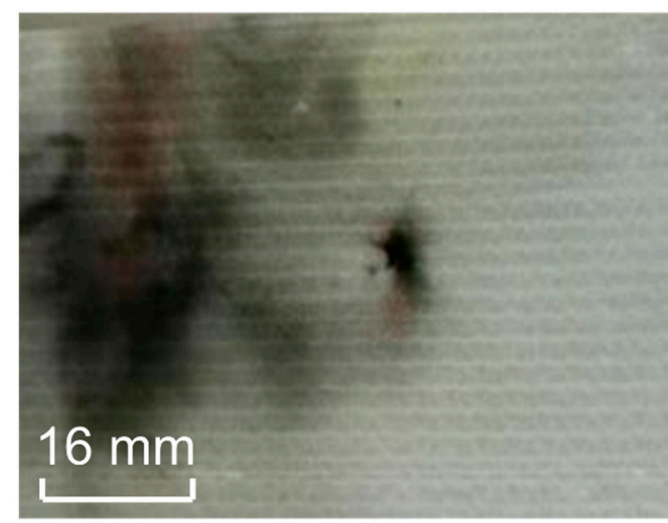

(b)

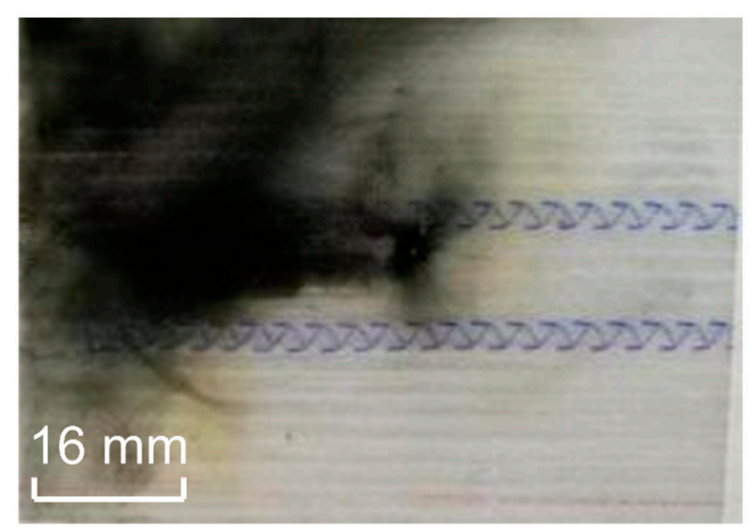

(c)

Figure 9. Damage morphology of GFRC laminates under different lightning current components, (a) component A, (b) component $\mathrm{B}$, (c) component $\mathrm{C}$.

In order to further study the influence of lightning current amplitude on the lightning ablation damage of GFRC materials, Haefely SSGA 200-180 ICG (Haefely, Basel, Switzerland) was used to simulate lightning currents with different amplitudes. In addition, three types of GFRC laminate with different thicknesses and layer orientation were selected in the surface lightning striking experiments to study the influence of material thickness and the layer orientation on the lightning striking damages. As depicted in Figure 10, the GFRC laminates with thicknesses of $1 \mathrm{~mm}, 2 \mathrm{~mm}$ and $4 \mathrm{~mm}$ were selected to conduct tests under current component A with an amplitude of $40 \mathrm{kA}$. The white part denotes delamination damage, while the dark black part denotes ablation damage. The other black parts on the surface are metal oxides sublimated by copper wire, which are not considered as ablation damage. As shown, the laminate with thickness of $1 \mathrm{~mm}$ was the most severely damaged. There are significant ablation marks on the surface of the GFRC laminate, and the delamination on the bottom side is obvious. However, there are no obvious thermal ablation marks on the surface of the laminates when the laminates thickness is greater 
than or equal to $2 \mathrm{~mm}$. The delamination on the bottom decreases with the increasing of thickness. Therefore, during creeping discharge, the main damage modes are epoxy resin pyrolysis and delamination. In addition, the thickness of the material is an important factor that affects the surface damage caused by lightning. Increasing in thickness for the GFRC laminate can effectively reduce the ablation damage degree caused by the lightning current.
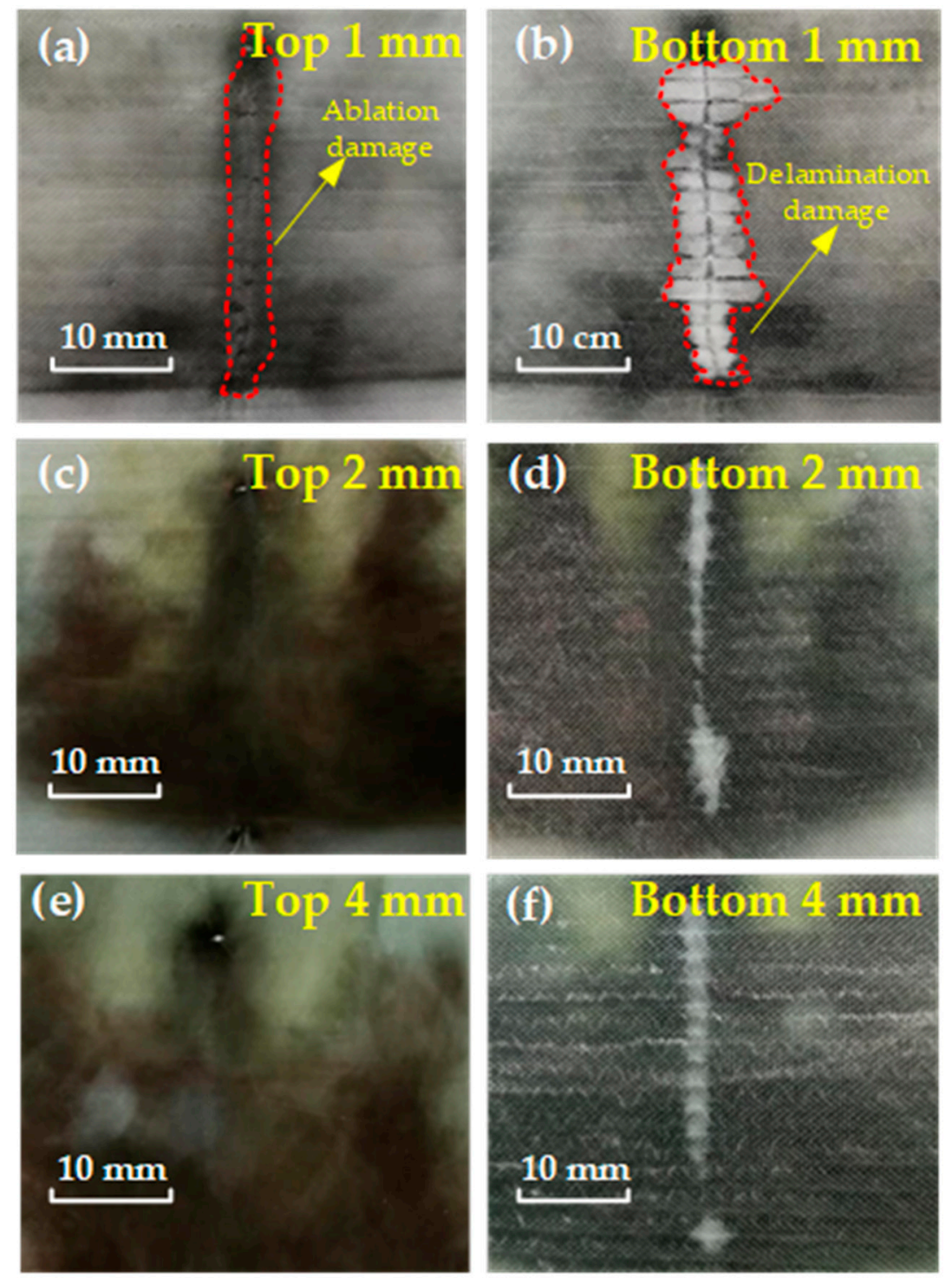

Figure 10. Damage status of GFRC laminates with different thicknesses under lightning current component A with an amplitude of $40 \mathrm{kA}$.

Figure 11 shows the comparison of the ablation damage area of the surface discharging along the fiber direction and the vertical fiber direction under the lightning current component A with an amplitude of $30 \mathrm{kA}$. It can be found that the damage area at both top and bottom faces in the laminate after discharging along the fiber direction is larger than that along vertical fiber direction discharge. Viewed from the bottom side, the epoxy resin pyrolyzed along the discharge direction and delamination also occurred. Since the thermal conductivity of GFRCs in the fiber direction is higher than that in other directions, the pyrolysis of epoxy resin mainly expands along the fiber direction.

Figure 12 shows the ablation areas of GFRCs with thicknesses of 1,2, and $4 \mathrm{~mm}$ under lightning striking with amplitudes of 10-50 kA lightning current were carried out along the fiber direction and perpendicular to the fiber direction. As shown, the damage area 
of the GFRC increases with the increase of current amplitude, while decreases with the increment of thickness. Furthermore, the damage area of GFRC with a thickness of $1 \mathrm{~mm}$ increases almost linearly with increasing current amplitude in the range up to $50 \mathrm{kA}$. The damage area of the GFRC when the lightning current discharge along the fiber direction was larger than that discharging perpendicular to the fiber direction. As the laminate thickness increased, the difference in damage area between the fiber direction and the perpendicular fiber direction gradually decreased. With increasing of the lightning current amplitude, the damage area and the difference between the two directions of the GFRC laminates increased. Therefore, the lightning current amplitude, the current direction, and the laminate thickness have an important influence on the ablation degree along the surface.

As shown in Figure 13, the internal damage of GFRC laminates was presented using the hot wire emission scanning electron microscope (SEM) VEGA3 produced by TESCAN company (Brno, Czech Republic). Two segments which cut at central and marginal region were used for SEM analysis to detect the internal characteristic of the GFRC with and without lightning striking damages. It can be found that the GFRC laminate without suffering lightning striking presented a complete structure, and the GF is tightly wrapped by epoxy resin and no obvious delamination is seen in Figure 13a. The microscopic characterization of the GFRC laminate after surface discharge ablation was illustrated in Figure 13b. It was clearly seen that the various damages modes including delamination, fiber breakages, and epoxy resin pyrolysis occurred in the laminate.
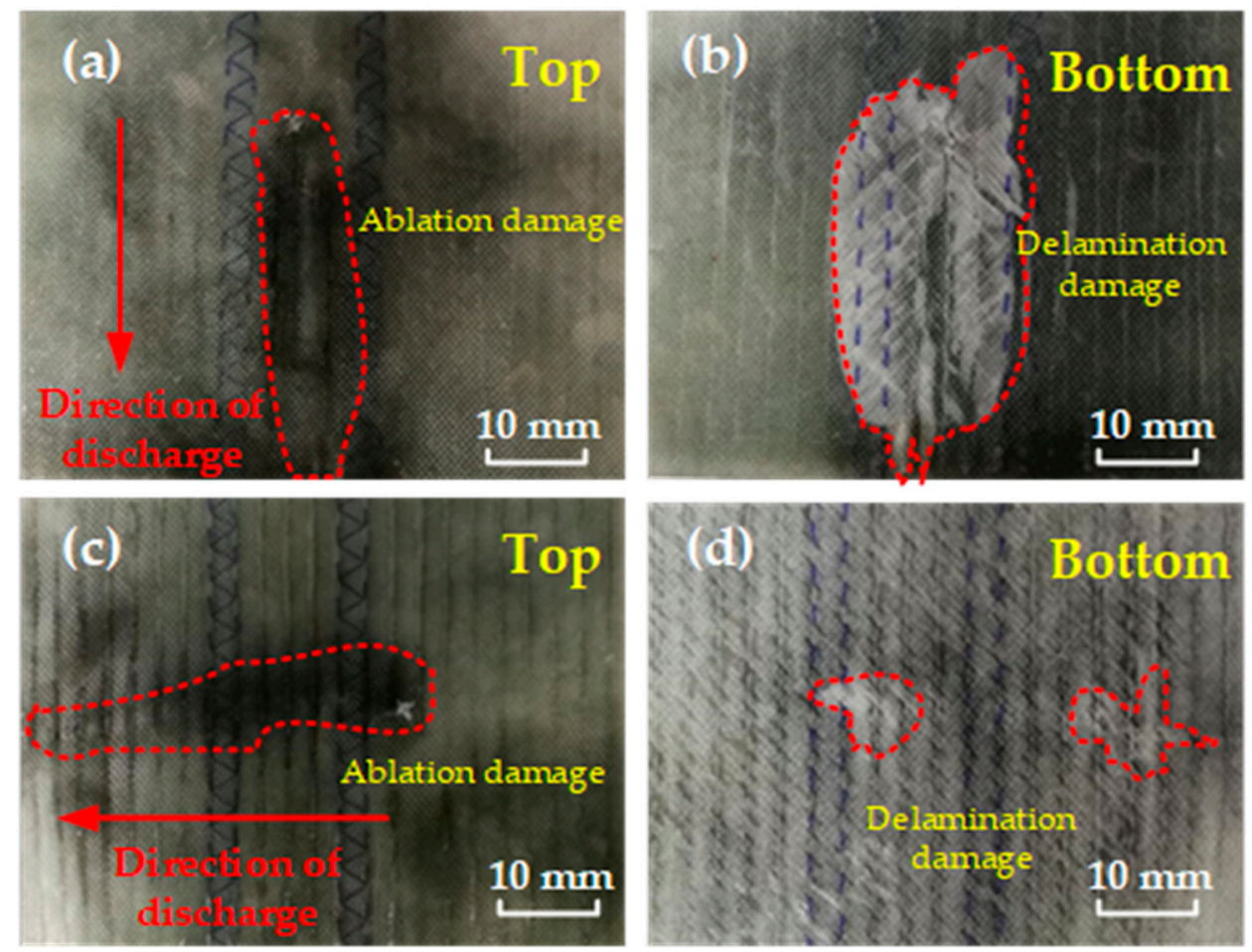

Figure 11. Damage area of the GFRCs under lightning current component $A$ with an amplitude of $30 \mathrm{kA},(\mathbf{a}, \mathbf{b})$ discharging along the fiber direction, $(\mathbf{c}, \mathbf{d})$ discharging perpendicular to the fiber direction. 


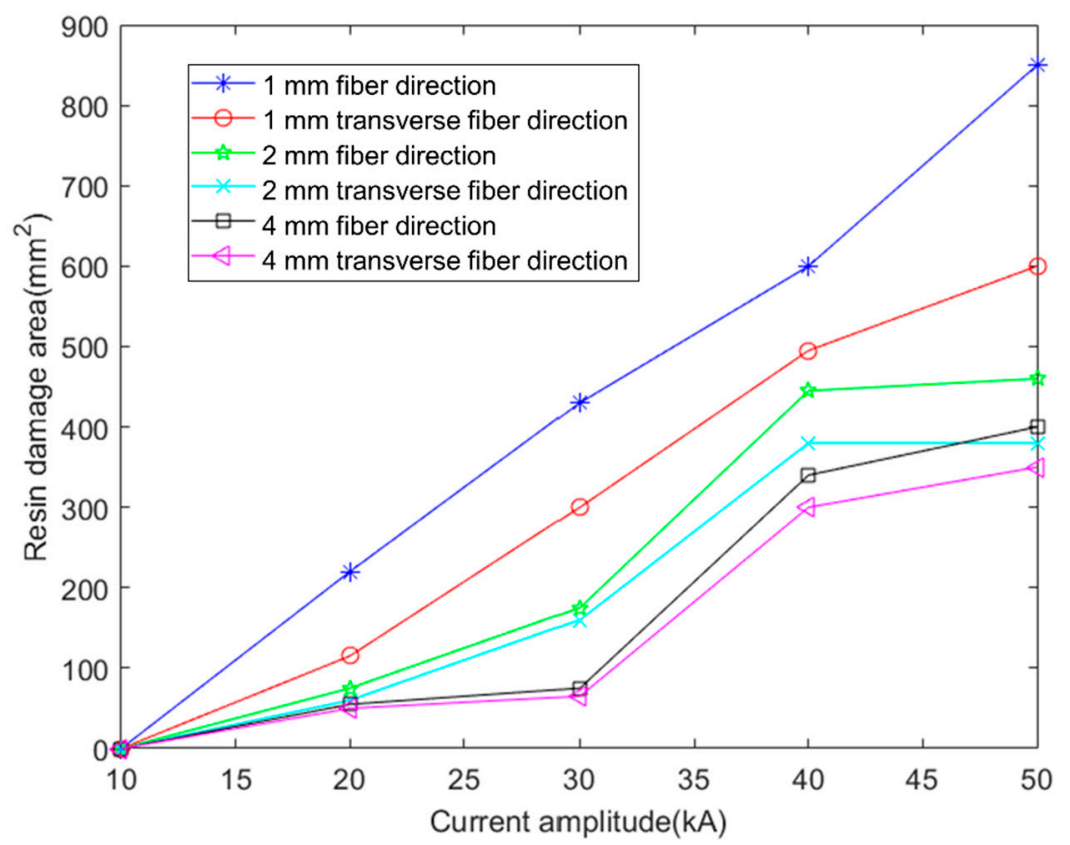

Figure 12. Influence of laminate thickness, discharge direction and lightning current amplitude on the creeping ablation damage area.
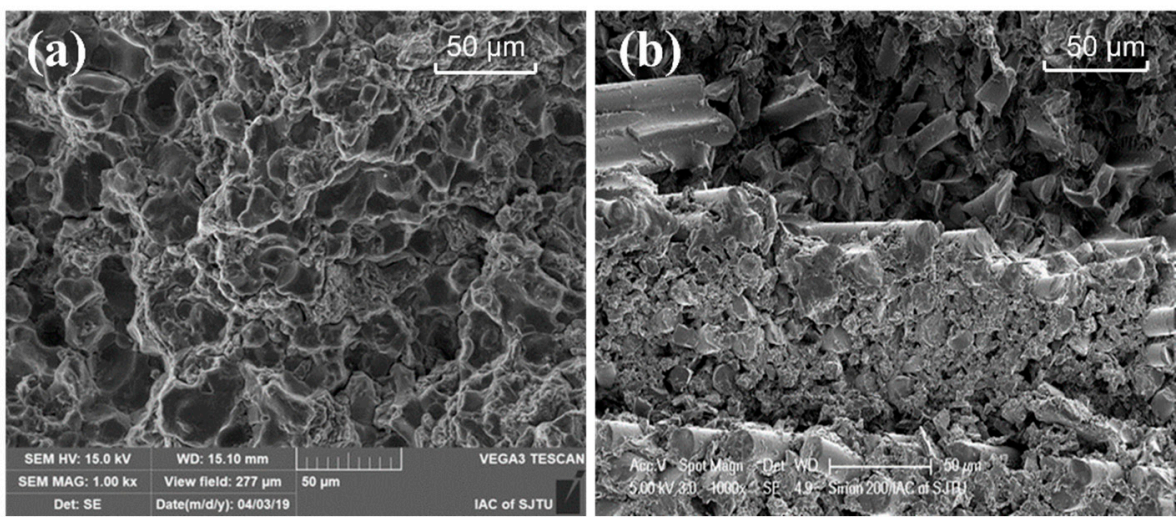

Figure 13. Scanning electron microscope (SEM) micrographs of GFRC laminates, (a) before lightning striking, (b) after lightning striking.

\subsubsection{Ablation Damages along the Thickness Direction}

The three lightning current components $\mathrm{A}, \mathrm{B}$, and $\mathrm{C}$ are used to conduct penetration ablation experiments on GFRC laminates. As depicted in Figure 14, the epoxy resin is quickly thermally decomposed and generate a large amount of gas when a throughthickness discharge induced by the current component A with a high amplitude acted on the GFRC laminate, and results in the local burst and mechanical damages. The effect of component $\mathrm{B}$ was least among the three components, and there was almost no damage under current component $B$. Since the duration of the component $C$ was greater than that of the component $\mathrm{A}$, the ablation damage aeras induced by component $\mathrm{C}$ is larger, and a circular perforation was created. It can be concluded that the component $C$ generated a lot of Joule heat due to its largest amount of charge transferred and was deemed as the most dangerous current component among these three currents.

There are two main types of lightning striking damages: one is thermal ablation damage, which is a high-temperature ablation phenomenon caused by the conversion of current into Joule heat during the conduction process. The other one mechanical damage 
such as fracture and delamination of the composite material, which is induced by the stress wave caused by the rapid gasification of the resin during high temperature pyrolysis.
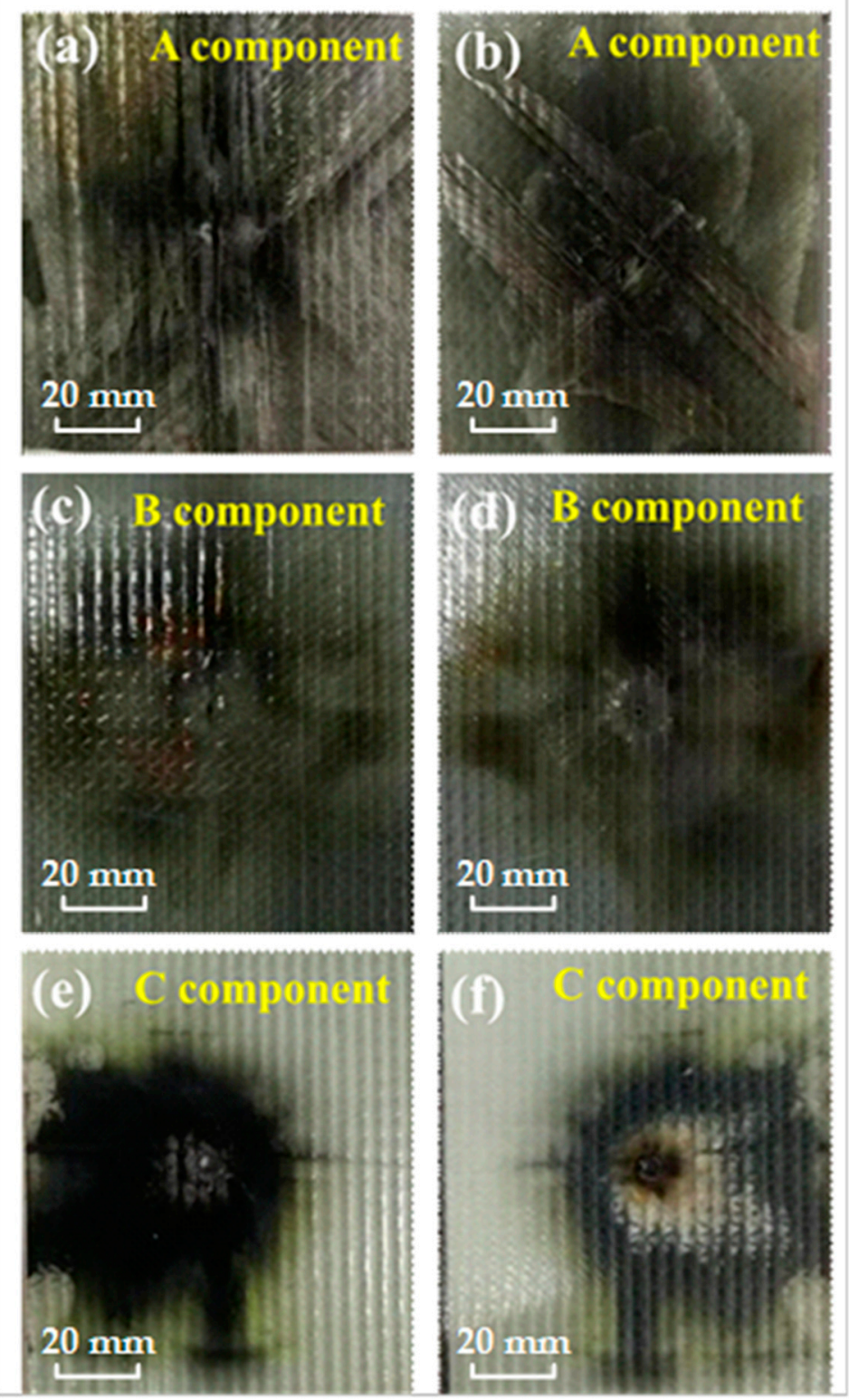

Figure 14. The experimental results of the through-discharge of the GFRCs under different lightning current components: (a,b) A component; (c,d) B component; (e,f) C component.

Figure 15 showed the penetration ablation damages of GFRCs under the current component A with amplitudes of $10 \mathrm{kA}, 30 \mathrm{kA}$, and $40 \mathrm{kA}$. Only the region near the attachment point was damaged when the amplitude is $10 \mathrm{kA}$. Delamination area with a size of about $100 \mathrm{~mm} \times 150 \mathrm{~mm}$ was caused when the amplitude reached $40 \mathrm{kA}$. Because as the current amplitude increased, the higher the energy passing through the needleshaped electrode and arc temperature increased, which leaded to an increase of the gas content in the thermal decomposition products of the epoxy resin. As it was difficult for gas generated inside the laminate to diffuse quickly, the volume of gas accumulated between the laminates increased. The gas exploded under the action of Joule heat and stress waves caused by the impulse current, causing fiber breakage and delamination of the laminate. This process also increased heat transfer, causing large areas of resin damage on the surface of the laminate. The experimental results showed that the fiber warpage was mainly distributed in the direction of $\pm 45^{\circ}$, indicating that the GF breakages were mainly 
affected by the layup orientation. In addition, some fibers also warped in other directions due to the non-uniformity of internal gas explosion. As the current amplitude increased, the penetrating damages of GFRC laminates became more and more serious.
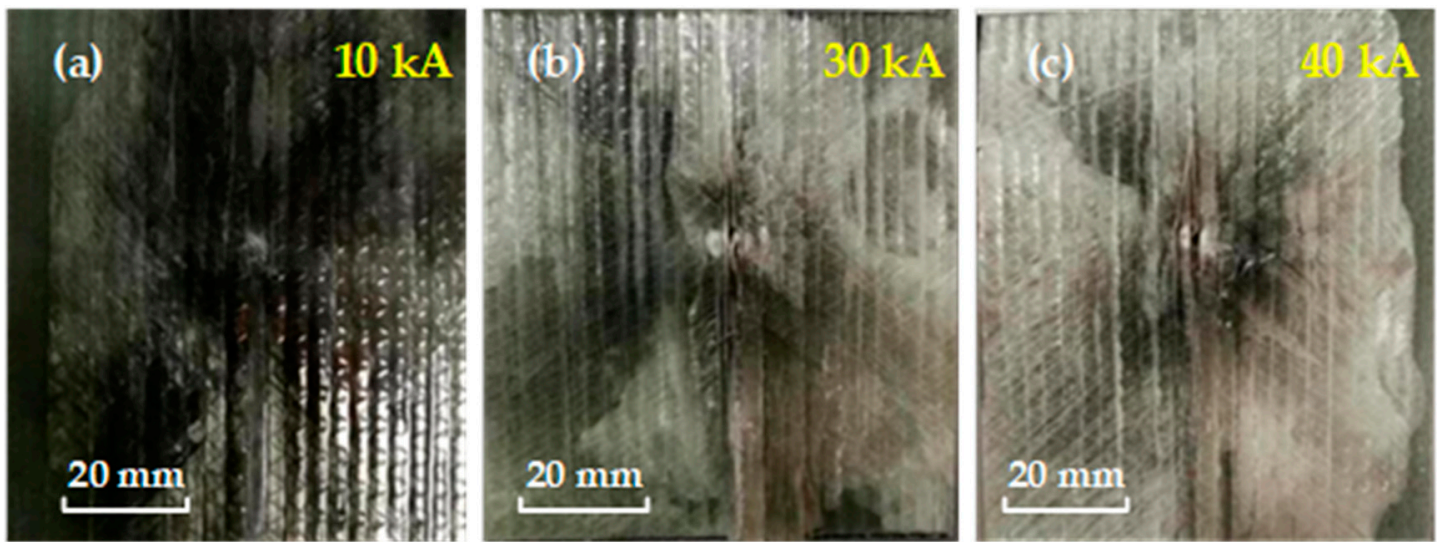

Figure 15. Ablation damages of GFRCs under different current amplitudes, (a) 10 kA, (b) 30 kA, (c) 40 kA.

Figure 16 shows the internal damages of GFRCs under current component $\mathrm{C}$ with an amplitude of $30 \mathrm{kA}$ by using SEM. It can be observed that the GF was obviously broken, and the internal structure became sparser. As shown in the red circle in Figure $16 c, d$, various micro-scale failure modes including fiber breakages, fiber pull-out, matrix cracking and delamination can be observed. This is because a large amount of gas produced by pyrolysis of epoxy resin during lightning striking resulted in the local explosion, and then caused stress wave, which promoting the mechanical damages.
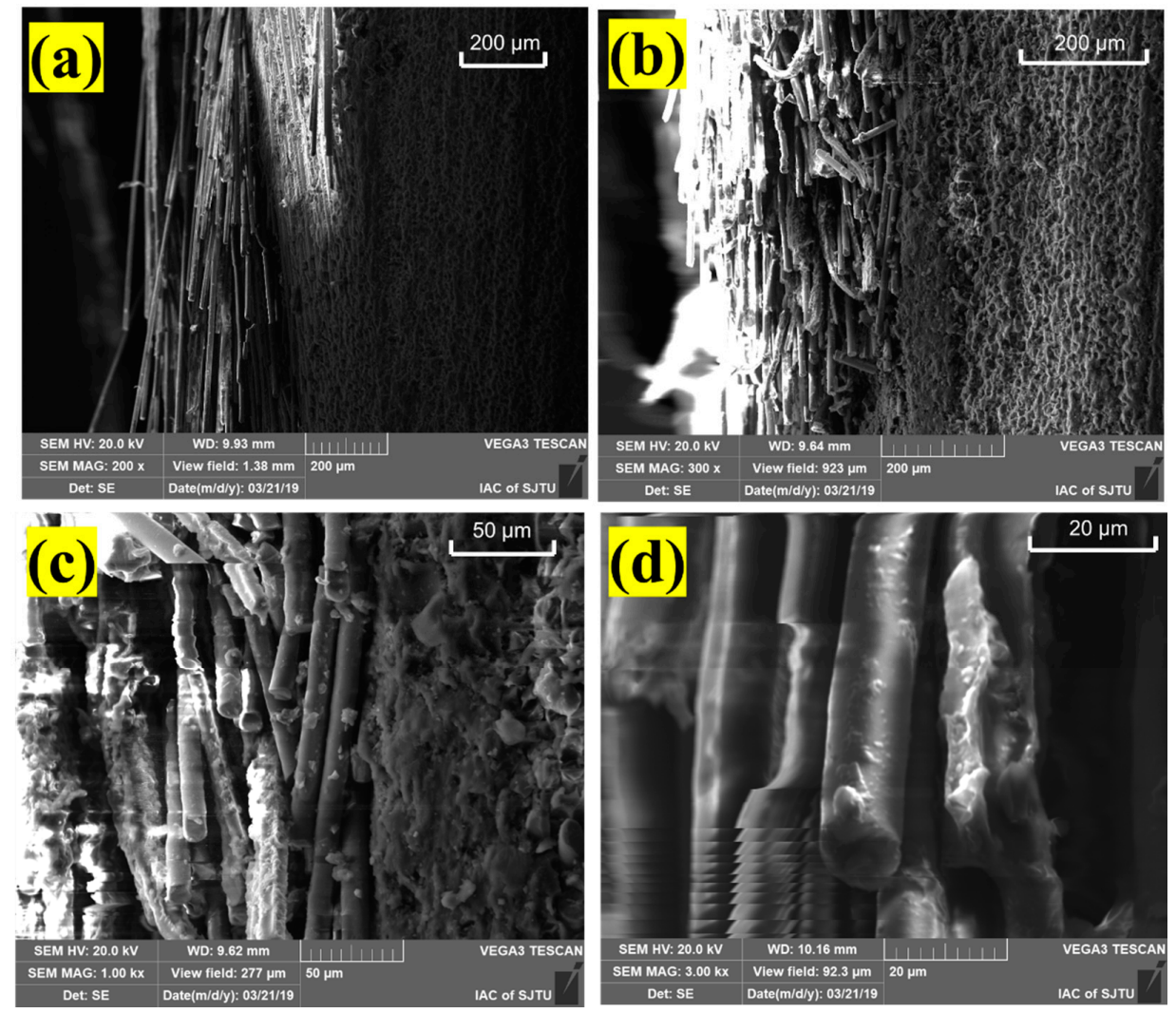

Figure 16. The microscopic morphology of the GFRC laminate after ablation with a $C$ component of $30 \mathrm{kA}$. With different magnification: (a) $200 \times$, (b) $300 \times$, (c) $1.00 \mathrm{k} \times$ and (d) $3.00 \mathrm{k} \times$. 


\subsection{Numerical Prediction of Lightning Ablation Damage}

\subsubsection{Simulation Analysis of GFRC Ablation Damage along the Surface}

The current component A with amplitudes of $10 \mathrm{kA}, 30 \mathrm{kA}$ and $50 \mathrm{kA}$ were used to simulate the lightning damage of the GFRC laminate, and compared well with the experimental results, as shown in Figure 17. The numerical results indicated that the GFRC laminate only has some slight damages at the attachment point at the front face when the lightning current amplitude is $10 \mathrm{kA}$. The damage does not touch the bottom of the laminate (see Figure 17a). A long and narrow ablation area in the direction of the ignited copper wire can be recognized when the lightning current amplitude reaches $30 \mathrm{kA}$, and damages have propagated to the bottom of the laminate (Figure 17b). As the current amplitude increased to $50 \mathrm{kA}$, the damage area is further expanded, and the ablation area on the bottom of the laminate began to extend perpendicular to the discharge channel toward both sides (see Figure 17c).

The experimental results showed that the GFRC laminates left a large amount of carbon material after copper wire sublimation under lightning striking with a current amplitude of $10 \mathrm{kA}$. However, no obvious damages were found on the bottom of composite (see Figure 17d). It was seen that a large amount of epoxy resin pyrolysis, GF breaks, and delamination occur in the laminate when the lightning current amplitude is $30 \mathrm{kA}$ and $50 \mathrm{kA}$ (see Figures 7 and 17e).

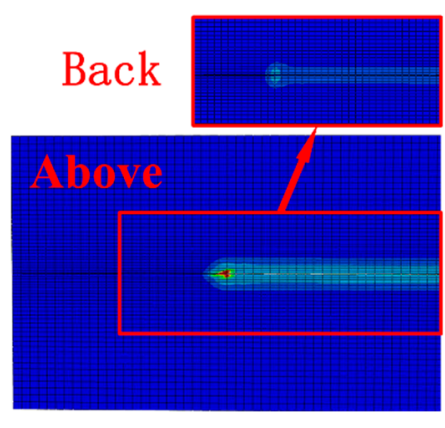

(a) $10 \mathrm{kA}$

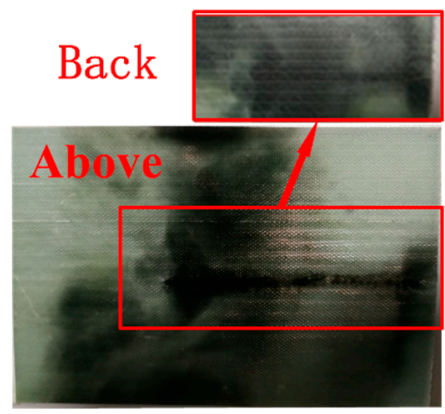

(d) $10 \mathrm{kA}$

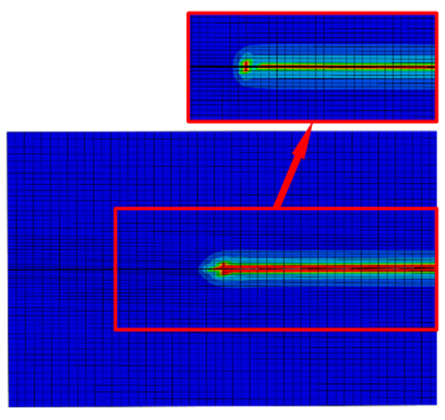

(b) $30 \mathrm{kA}$

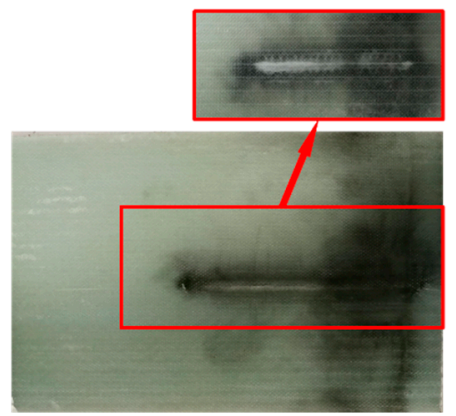

(e) $30 \mathrm{kA}$

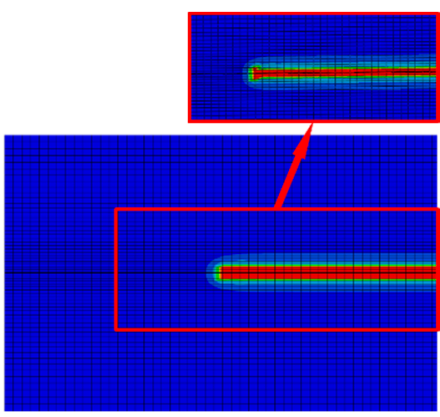

(c) $50 \mathrm{kA}$

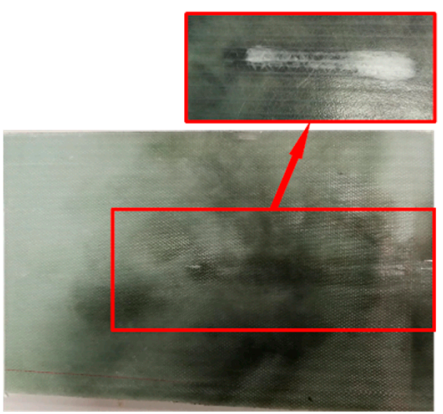

(f) $50 \mathrm{kA}$

Figure 17. Comparison of lightning strike experiment and simulation damage of GFRC laminate under different peak values.

It was found that the damage mainly includes epoxy resin ablation by high temperature decomposition and GF fractured by shock wave [24]. Both damage forms have a great effect on the mechanical strength of the GFRC laminate. The experimental ablation area was defined by the area where the surface epoxy resin was decomposed and carbonized, the GF breakage and delamination. The damage status of the laminate obtained from simulation model is determined according to the surface temperature distribution cloud map. It is defined that ablation damage occurs when the surface temperature exceeds the range of $600{ }^{\circ} \mathrm{C}$. The surface ablation damage aera in the GFRC obtained by experiment 
and simulation are compared in Table 3. The maximum area error is only $6.68 \%$. It can be concluded that the experimental results are in good agreement with the simulation results.

Table 3. Comparison of surface ablation damage area $\left(\mathrm{mm}^{2}\right)$ between experiment and simulation.

\begin{tabular}{cccc}
\hline & $\mathbf{1 0} \mathbf{~ k A}$ & $\mathbf{3 0 ~ k A}$ & $\mathbf{5 0 ~ k A}$ \\
\hline Experimental & 6.73 & 89.43 & 396.85 \\
Simulation & 6.29 & 86.72 & 381.59 \\
\hline
\end{tabular}

The lightning current with an amplitude ranging from $10 \mathrm{kA}$ to $100 \mathrm{kA}$ were chosen to study the different current amplitudes on the lightning striking damage by using the proposed FE thermal-electric coupling model. The corresponding numerical calculation result is shown in Figure 18a. Then, a nonlinear functional relationship between damage aera and current amplitude is derived by data fitting method. The fitting equation is expressed by Equation (16), and the $R^{2}$ is 0.92 :

$$
y=-174.16+14.05 x-0.07651 x^{2}
$$

where $x$ means current, the unit is $\mathrm{kA}$; $y$ means the damage area, the unit is $\mathrm{mm}^{2}$.

It can be found from Equation (16) that the GFRC damage area is positive correlation with the lightning current amplitude. The growth rate of the damage area slows down when the peak value is greater than $60 \mathrm{kA}$. The damage area is almost increased to $500 \mathrm{~mm}^{2}$ and tends to be saturated when the lightning current amplitude reaches $100 \mathrm{kA}$.

Figure $18 \mathrm{~b}$ shows the relationship between the surface damage area of the GFRC material and the amount of charge Qs (As). The fitting relationship can be expressed by Equation (17), and the $R^{2}$ of this expression is 0.99 :

$$
y=317.77-698.1 e^{-0.0988 x}
$$

where $x$ represents the amount of charge, the unit is As; $y$ represents the damage area, the unit is $\mathrm{mm}^{2}$.

Figure $18 \mathrm{c}$ shows the relationship between the GFRC creeping damage area and the specific energy $\mathrm{W} / \mathrm{R}(\mathrm{kJ} / \Omega)$. The corresponding fitting curve can be expressed by Equation (18), and the $R^{2}$ of this expression is 0.99 :

$$
y=458.94-477.55 e^{-0.0029 x}
$$

where $x$ means specific energy, the unit is $\mathrm{kJ} / \Omega$.

It can be seen from Equations (16)-(18) that the damage area is positively non-linearly related to the amplitude of the lightning current, the amount of charge, and the specific energy. In the initial stage of lightning striking, the damage area increases rapidly with the increment of influence parameters (current amplitude, amount of charge, specific energy), and then the growth rate slows down and tends to a constant value (about $450 \mathrm{~mm}^{2}$ ).

Figure 19 shows a schematic diagram of the pulse current waveform, where $\mathrm{T}_{1}$ corresponds to the peak current $I_{\text {imp }}$ time, and $\mathrm{T}_{2}$ corresponds to the time when the peak current decays to $50 \%$.

Figure 20 shows the surface temperature distribution of GFRC laminates under the current component A with an amplitude of $50 \mathrm{kA}$. As shown in Figure 20, the temperature of the lightning current attachment point of the composite laminate reaches $1100{ }^{\circ} \mathrm{C}$ when the lightning current attaches to the GFRC laminate $\left(\mathrm{T}_{1}=1.6821 \times 10^{-5} \mathrm{~s}\right)$. Afterwards, the ablative damage area starts to develop towards the zero-potential edge of the GF reinforced composite laminate, as shown in Figure 20b. A clear ablation aera along the arc channel can be recognized at $\mathrm{T}_{2}\left(2.9627 \times 10^{-4} \mathrm{~s}\right)$, as shown in Figure 20e. It can be concluded that the lightning-induced ablation damages start to appear in the laminate at $T_{1}$ and tend to be stable after $\mathrm{T}_{2}$. 


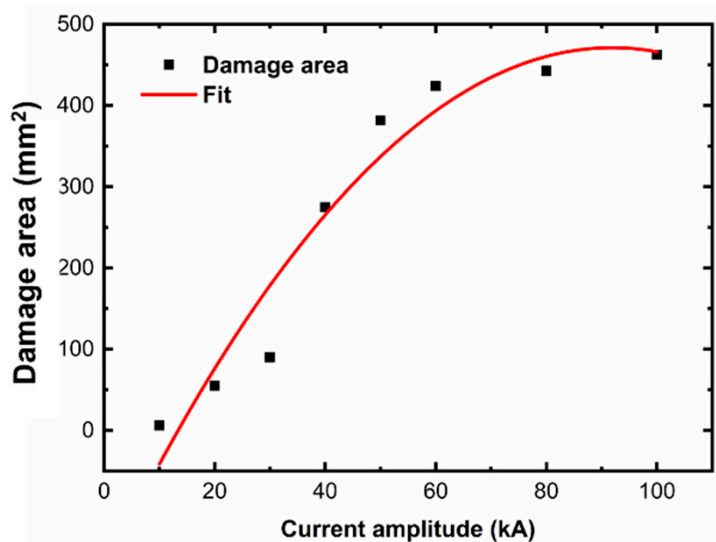

(a)

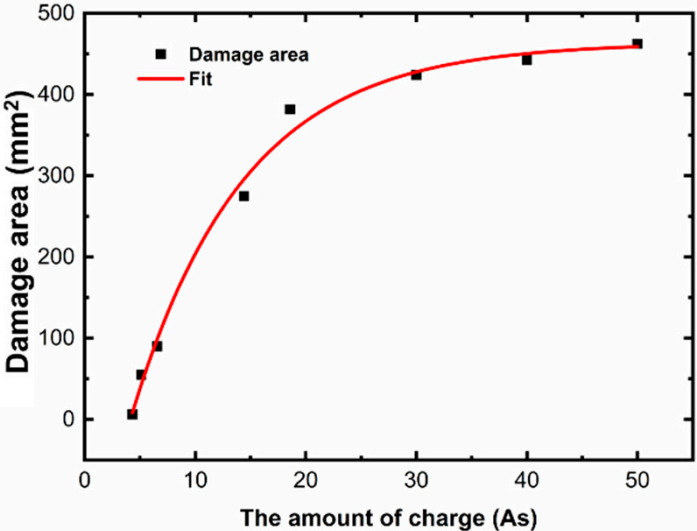

(b)

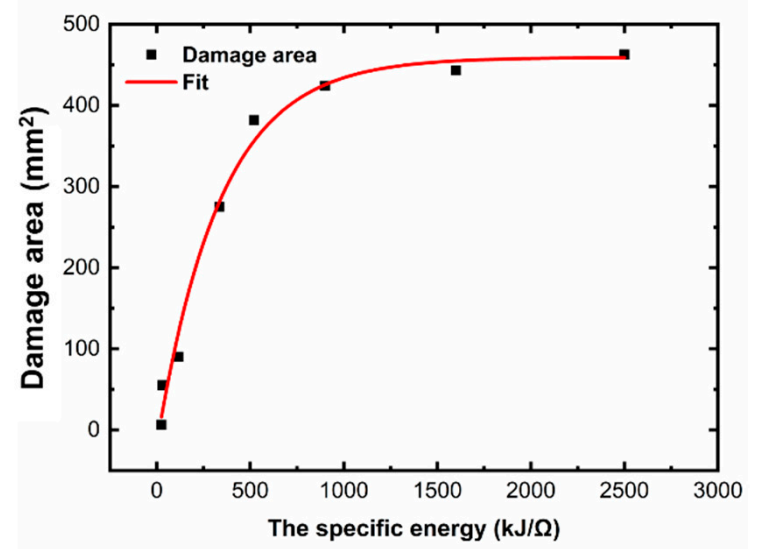

(c)

Figure 18. The relationship between GFRC creeping damage area and lightning current parameters, (a) damage area versus current amplitude curve, (b) damage area versus charge amount curve, (c) damage area versus specific energy curve.

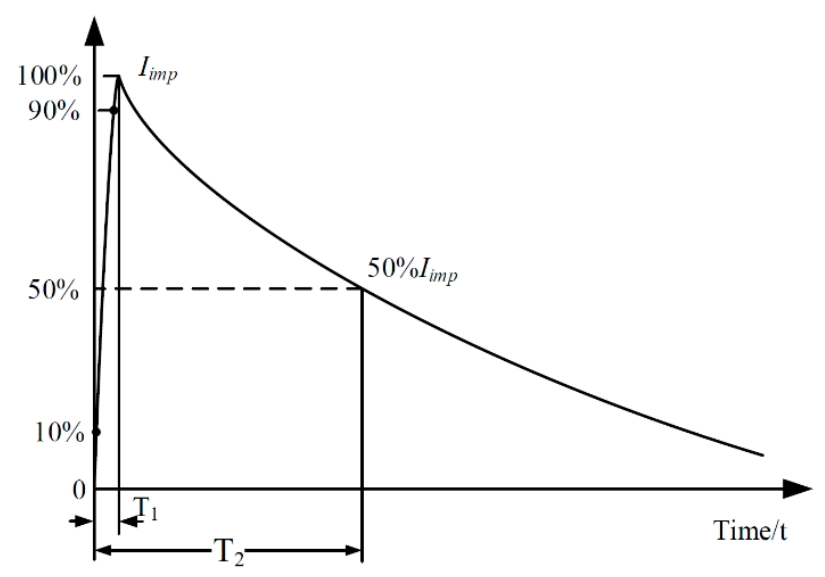

Figure 19. The schematic diagram of pulse current waveform. 


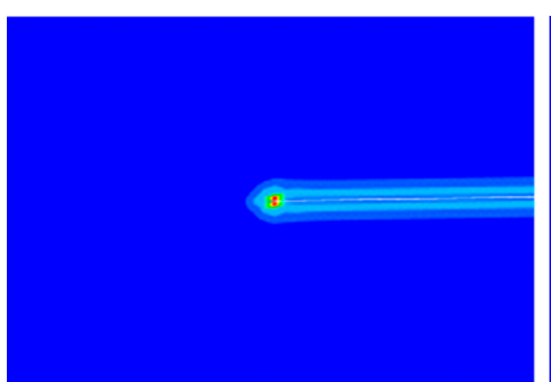

(a) $8.99 \times 10^{-7} \mathrm{~s}$

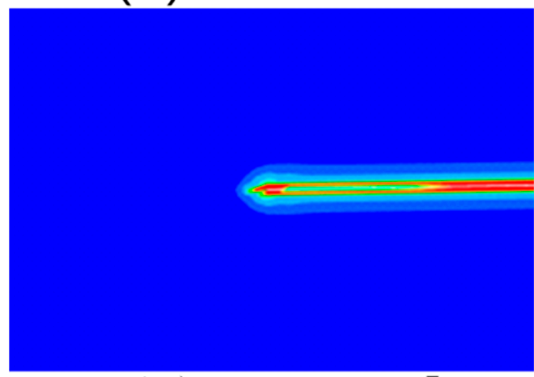

(c) $2.27 \times 10^{-5} \mathrm{~s}$

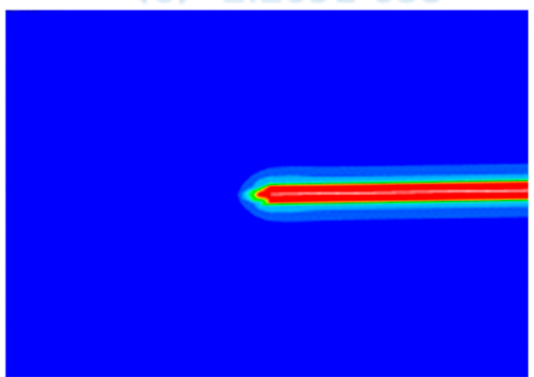

(e) $2.96 \times 10^{-4} \mathrm{~s}$

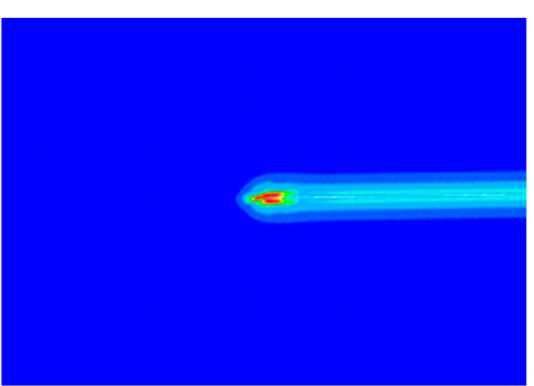

(b) $1.68 \times 10^{-5} \mathrm{~s}$

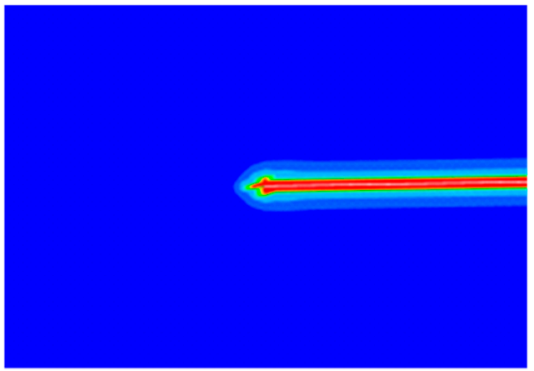

(d) $3.08 \times 10^{-5} \mathrm{~s}$

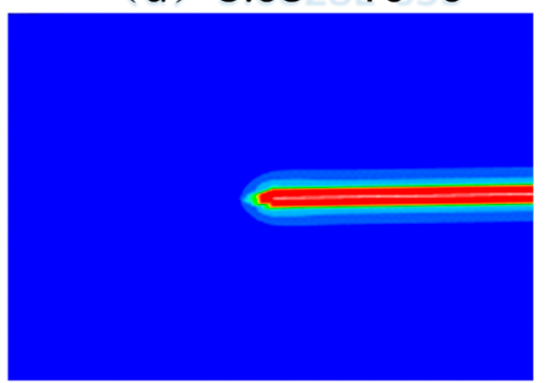

(f) $8.00 \times 10^{-4} \mathrm{~s}$
SOV2

(Avg: 75\%)

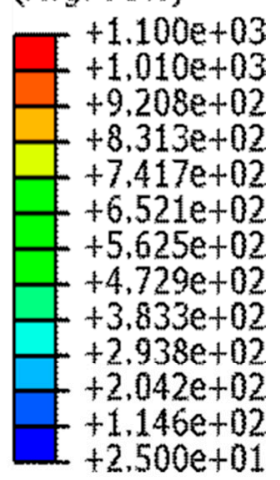

Figure 20. The temperature distribution cloud map of the surface of the composite laminate under the action of $50 \mathrm{kA}$ lightning current at different moments.

\subsubsection{Simulation Analysis of GFRC Ablation Damage along the Thickness}

The lightning-induced ablation damage of GFRC under the current component $C$ with an amplitude $300 \mathrm{~A}$ after $0.5 \mathrm{~s}$ was compared with the experimental results. It can be found from Figure 21 that the epoxy resin decomposes around the attachment point, and the ablation aera have a circular ablation shape.

The lightning-induced ablation of GFRC under the current component $C$ with amplitudes of 150 A, 200 A, 250 A, 300 A, and 350 A were calculated numerically, and the comparison of the ablation damage to the experimental results are shown in Table 4. As shown, the maximum difference between simulation and experiment results is only $0.82 \mathrm{~mm}^{2}$, and the maximum error percentage is $4.9 \%$. The damage aera versus current amplitude curves obtained from numerical and experimental method are very close as depicted in Figure 22. Hence, the proposed FE thermal-electric coupling model predict lightning striking damage of GFRCs very well.

Table 4. Comparison of penetration ablation damage area between the experiment and simulation.

\begin{tabular}{cccccc}
\hline Current Amplitude & $150 \mathrm{~A}$ & $200 \mathrm{~A}$ & $250 \mathrm{~A}$ & $300 \mathrm{~A}$ & $350 \mathrm{~A}$ \\
\hline Experiment & 17.21 & 18.78 & 20.74 & 22.35 & 23.34 \\
Simulation & 16.39 & 18.36 & 20.56 & 22.23 & 23.07 \\
\hline
\end{tabular}




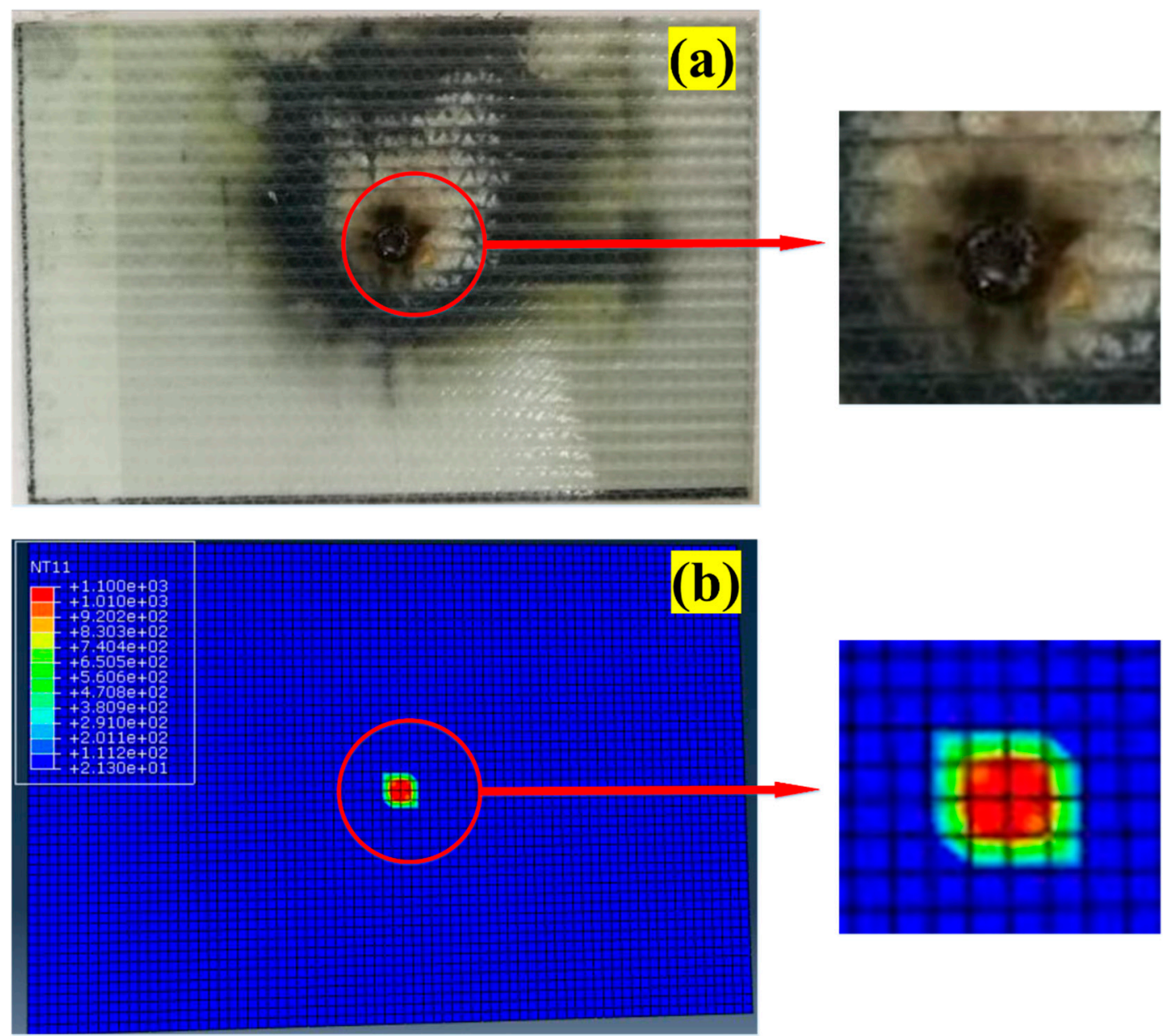

Figure 21. Comparison of ablation damage obtained by the simulation and experiment, (a) experimental result, (b) simulation result.

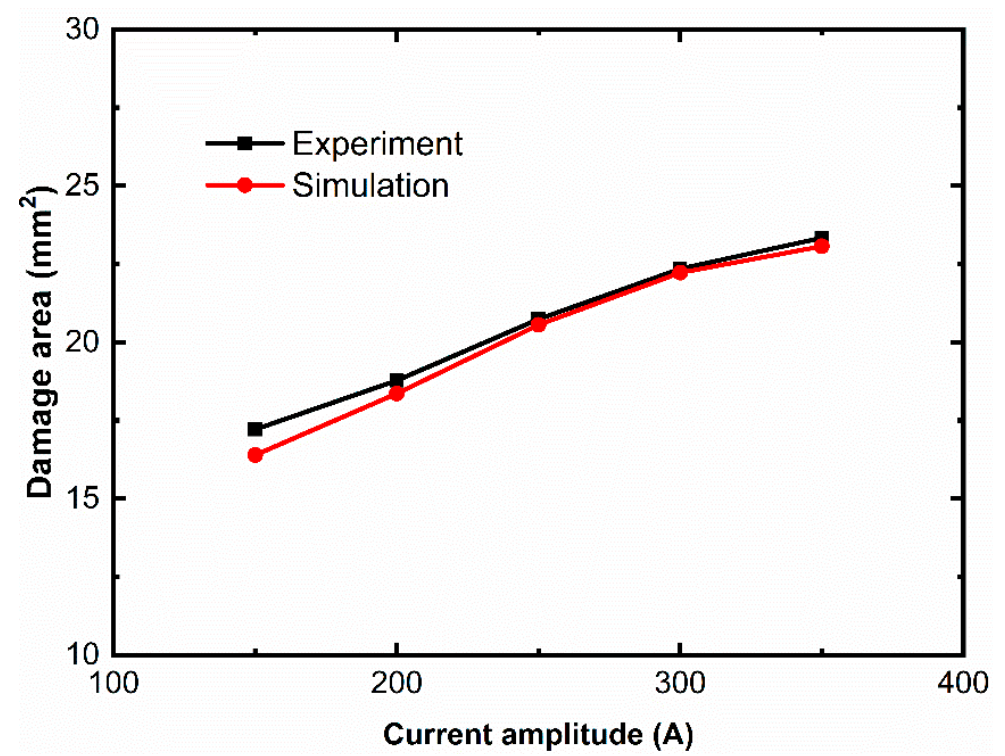

Figure 22. Lightning striking damage aera versus current amplitude curves.

The ablation aera of GFRC under the current component $\mathrm{C}$ with amplitudes of $400 \mathrm{~A}$, $500 \mathrm{~A}, 600 \mathrm{~A}, 700 \mathrm{~A}$, and $800 \mathrm{~A}$ were also calculated to provide more effective data for establishing the function relationships between damage areas and the lightning current 
parameters. Figure 23a shows the relationship between the GFRC penetration damage area and the current amplitude of the component $C$. The corresponding function relationship can be expressed as Equation (19) by data fitting, and the $R^{2}$ is 0.96 :

$$
y=40.26-28.57 e^{-0.0014 x}
$$

where $x$ represents the current and $y$ represents the damage area.

Figure 23b shows the relationship between the penetration damage area of GFRC and the charge amount of the current component $C$. The function relationship is written as Equation (20), and the $R^{2}$ is 0.96 :

$$
y=40.25-28.57 e^{-0.0028 x}
$$

where $x$ represents charge amount $(A s)$ and $y$ represents the damage area.

Figure $23 \mathrm{c}$ shows the relationship between GFRC penetration damage area and specific energy, and the function relationship is given as Equation (21), the $R^{2}$ is 0.93 :

$$
y=31.838-15.35 e^{-0.016 x}
$$

where $x$ denotes specific energy, the unit is $\mathrm{kJ} / \Omega$; $y$ means the damage area.

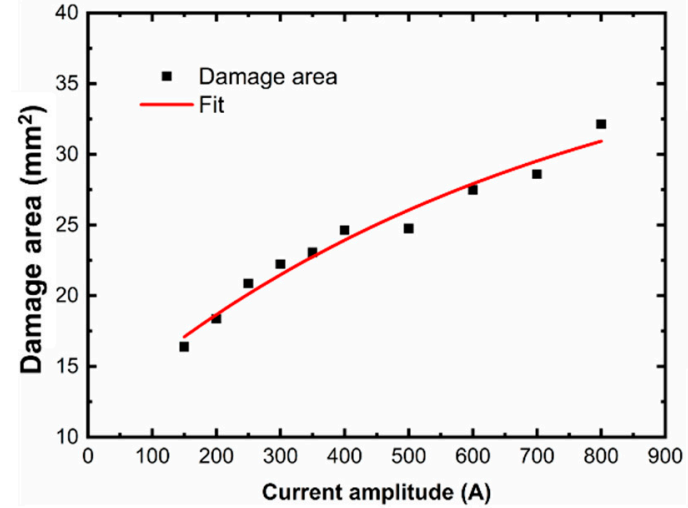

(a)

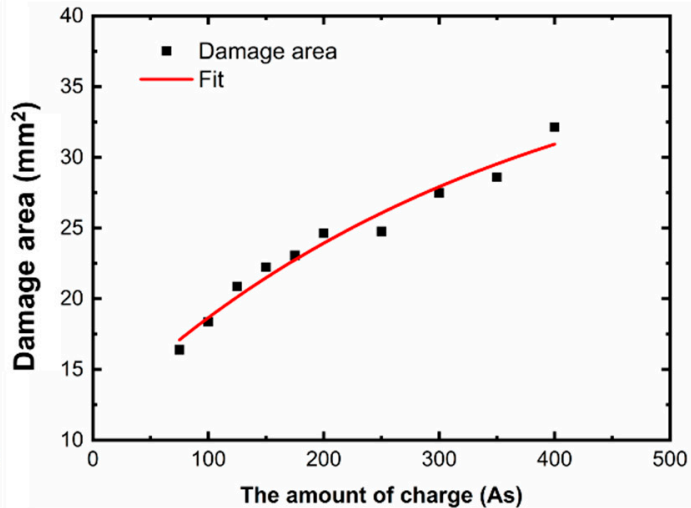

(b)

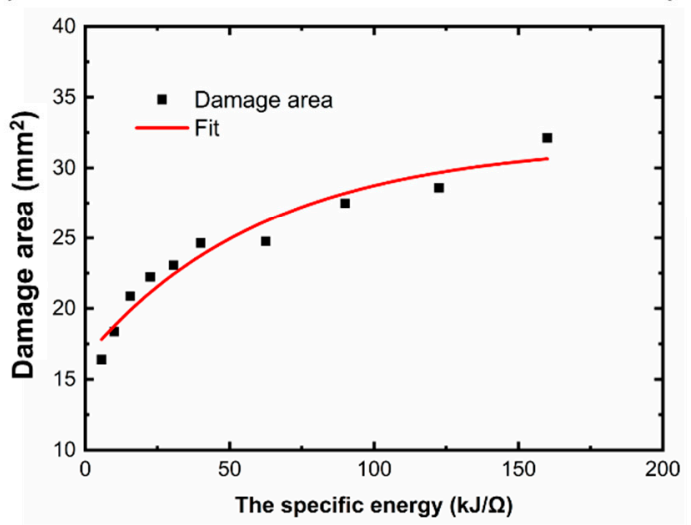

(c)

Figure 23. The relationship between penetration damage area and current parameters, (a) damage area versus current amplitude curve, (b) damage area versus charge amount curve, (c) damage area versus specific energy curve.

Figure 24 shows the ablation damage history of the GFRC laminate under the lightning current component $C$. The results show that when the lightning current $C$ component with an amplitude of $800 \mathrm{~A}$ acts on the laminate for $0.03,125 \mathrm{~s}$, the temperature of the epoxy resin at the attachment point reaches $617^{\circ} \mathrm{C}$. The epoxy resin has been completely decomposed. 
After $0.0468 \mathrm{~s}$, the maximum temperature of the attachment point reached $1100{ }^{\circ} \mathrm{C}$, and the GF began to sublime. After $0.0875 \mathrm{~s}$, the ablation damage area tends to be stable, and the value is about $32.1322 \mathrm{~mm}^{2}$.

Figure 25 shows temperature distribution cloud diagram along the thickness direction of the GFRCs under current component $C$ with an amplitude of $800 \mathrm{~A}$. The maximum surface temperature of the GFRC laminate reaches $898^{\circ} \mathrm{C}$ at $0.03906 \mathrm{~s}$, which results in epoxy resin pyrolysis and GF breakages. At $0.046875 \mathrm{~s}$, the temperature in this area reaches $1100{ }^{\circ} \mathrm{C}$ and the GF begins to sublime. The epoxy resin in the damaged area is completely decomposed at $0.5 \mathrm{~s}$, and the ablation depth of the resin is $0.308 \mathrm{~mm}$. The sublimation depth of the GF is $0.107 \mathrm{~mm}$. Since the interlayer temperature between the first layer and the seco d layer is only $183{ }^{\circ} \mathrm{C}$ which is less than the pyrolysis temperature of the resin, the epoxy resin in this interlayer has no thermal decomposition.

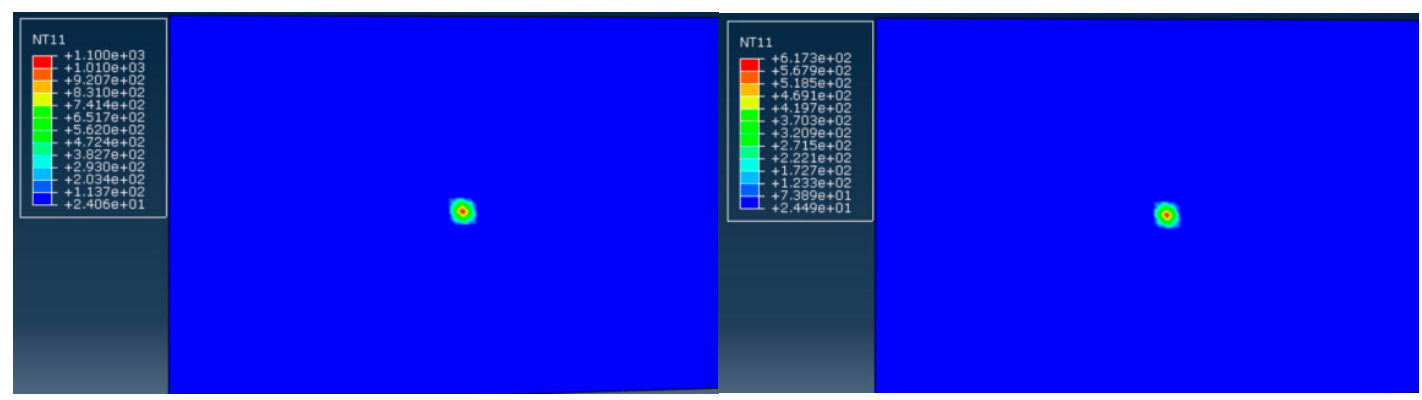

(a) $0.03125 \mathrm{~s}$

(b) $0.0468 \mathrm{~s}$
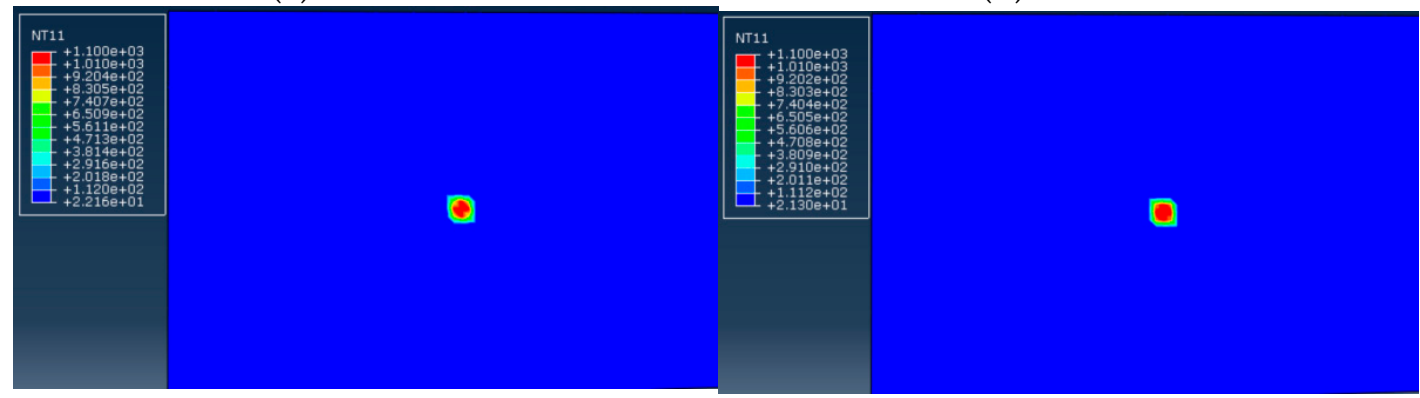

(c) $0.0875 \mathrm{~s}$

(d) $0.5 \mathrm{~s}$

Figure 24. The temperature distribution cloud map of at the front face of the GFRC laminate under the component $C$ with an amplitude of $800 \mathrm{~A},(\mathbf{a})$ at $0.03125 \mathrm{~s},(\mathbf{b})$ at $0.0468 \mathrm{~s},(\mathbf{c})$ at $0.0875 \mathrm{~s},(\mathbf{d})$ at $0.5 \mathrm{~s}$.

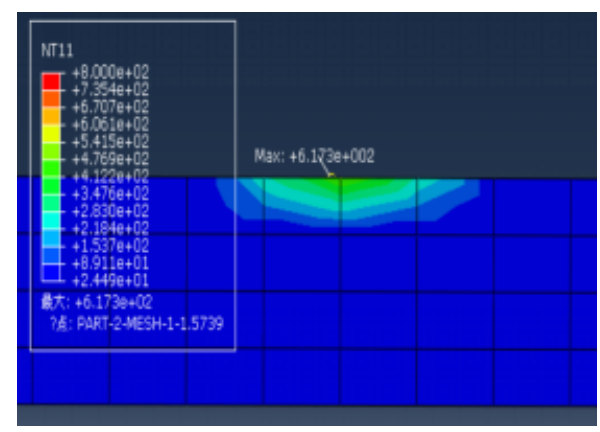

(a) $0.03125 \mathrm{~s}$

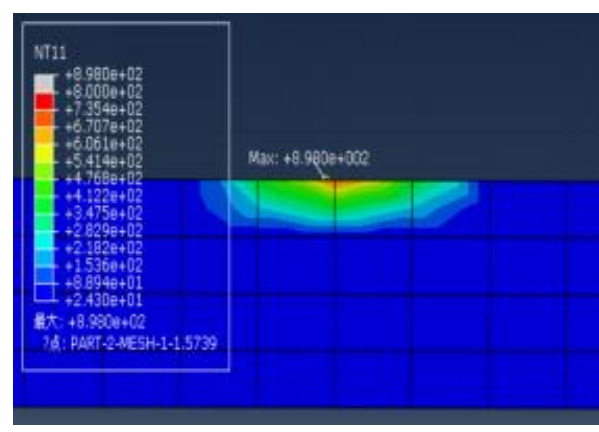

(b) $0.03906 \mathrm{~s}$

Figure 25. Cont. 


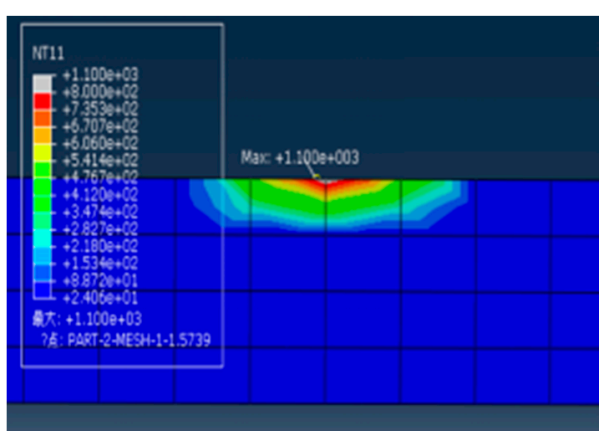

(c) $0.046875 \mathrm{~s}$

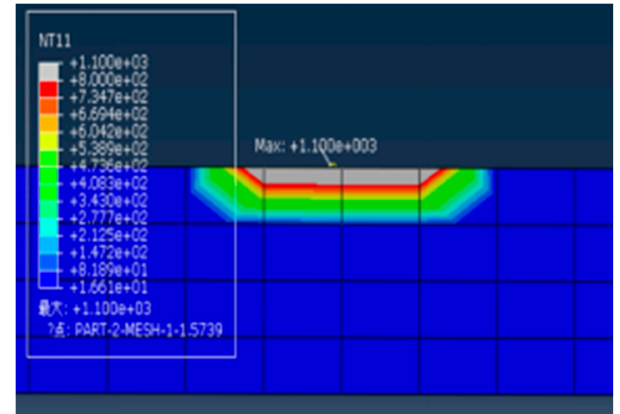

(d) $0.2358 \mathrm{~s}$

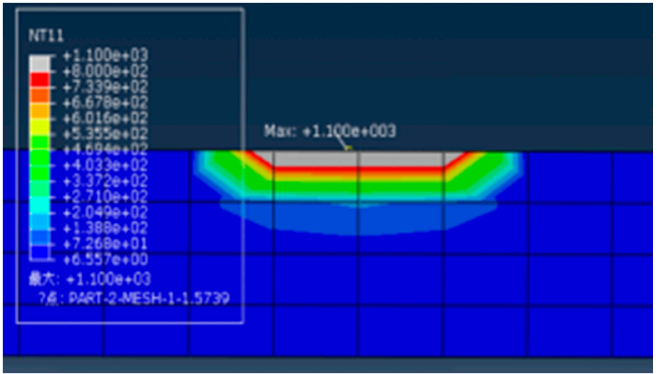

(e) $0.5 \mathrm{~s}$

Figure 25. Temperature distribution cloud diagram along the thickness direction at different moments, (a) at $0.03125 \mathrm{~s},(\mathbf{b})$ at $0.03906 \mathrm{~s},(\mathbf{c}) 0.046875 \mathrm{~s},(\mathbf{d})$ at $0.2358 \mathrm{~s},(\mathbf{e}) 0.5 \mathrm{~s}$.

\section{Conclusions}

This paper investigated the ablative damage characteristics of the GFRC used in wind turbine blades with three lightning current components $\mathrm{A}, \mathrm{B}$, and $\mathrm{C}$ by the experimental method. Due to the complex physics nature of lightning, quantifying the effect of the dynamic mechanical pressures induced by lightning strikes is very difficult. Hence, a thermal-electric coupling model without considering the effects of mechanical pressures for predicting the lightning ablation of the material was established. Three conclusions are drawn as follows:

1. The experimental results showed that the damage of GFRC is mainly affected by the component $\mathrm{A}$, while the influence of the components $\mathrm{B}$ and $\mathrm{C}$ can be ignored. The material thickness, layer direction, and lightning current parameters are all important factors for the ablation of GFRC under lightning strike.

2. Due to the high temperature pyrolysis of the resin and the rapid gasification of the resin during lightning strikes, the stress wave is produced which in turn leads to the fiber breakage and delamination.

3. A thermal-electric coupling simulation model is established, and the simulation results are in good agreement with the experimental results, which verifies that the model can be used to predict the lightning damage of GFRC. The quantitative relationship between the ablation area and the lightning current amplitude, charge amount and specific energy is obtained by data fitting. It can be found that the damage area and the depth of GFRC are positively non-linearly correlated with the lightning current amplitude, the charge amount and the specific energy.

Lightning striking causes serious damages to GFRCs around the lightning attachment points, including burning and vaporization and delamination since the electrical conductivity of GFRCs is much lower than that of metals. Attaching copper mesh on the GFRC will be helpful for the application of GFRC materials in wind turbine blades. A possible future line of investigation is to develop a multi physical field coupling model considering mechanical damage to analyze the damage mechanism of GFRCs with copper mesh protection layers. 
Author Contributions: Conceptualization, Y.Z. (Yang Zhao) and B.Y.; methodology, Y.Z. (Yang Zhao); software, Y.Z. (Yao Zhang); validation, Y.Z. (Yang Zhao), Y.Z. (Yao Zhang) and B.Y.; formal analysis, B.Y.; investigation, Y.Z. (Yang Zhao); resources, B.Y.; data curation, Y.Z. (Yang Zhao); writingoriginal draft preparation, Y.Z. (Yang Zhao) and Y.Z. (Yao Zhang); writing-review and editing, Y.Z. (Yang Zhao) and Y.Z. (Yao Zhang); visualization, Y.Z. (Yao Zhang) and B.Y.; supervision, B.Y.; project administration, Y.Z. (Yang Zhao); funding acquisition, Y.Z. (Yang Zhao). All authors have read and agreed to the published version of the manuscript.

Funding: The authors are grateful for the Fund of the Social Development Projects of STCSM (19DZ1201402).

Institutional Review Board Statement: Not applicable.

Informed Consent Statement: Not applicable.

Data Availability Statement: Not applicable.

Conflicts of Interest: The authors declare no conflict of interest.

\section{References}

1. Zhu, H.; Fu, K.; Yang, B.; Li, Y. Nickel-coated nylon sandwich film for combination of lightning strike protection and electromagnetic interference shielding of CFRP composite. Compos. Sci. Technol. 2021, 207, 108675. [CrossRef]

2. Hirano, Y.; Yokozeki, T.; Ishida, Y.; Goto, T.; Takahashi, T.; Qian, D.; Ito, S.; Ogasawara, T.; Ishibashi, M. Lightning damage suppression in a carbon fiber-reinforced polymer with a polyaniline-based conductive thermoset matrix. Compos. Sci. Technol. 2016, 127, 1-7. [CrossRef]

3. Zhang, J.; Zhang, X.; Cheng, X.; Hei, Y.; Xing, L.; Li, Z. Lightning strike damage on the composite laminates with carbon nanotube films: Protection effect and damage mechanism. Compos. Part B Eng. 2019, 168, 342-352. [CrossRef]

4. Zhao, J.; Chen, X.; Zhang, Y.; Zhang, B. Simulation and test for the lightning damage of the glass fiber composites. FRP/Compos. Mater. 2015, 1, 42-47.

5. Tao, S.; Liu, M.; He, M.; Yue, Y. Experimental study on lightning damage of glass fiber composite wind turbine blades. Bonding 2021, 46, 60-63.

6. Yang, C.; Zhao, Y.; Xiao, Y.; Xing, H.; Fu, Z. Experimental study on creepage of GFRP under simulate lightning current. Compos. Mater. Sci. Eng. 2020, 5, 47-52.

7. Guo, Y.; Xu, Y.; Wang, Q.; Dong, Q.; Yi, X.; Jia, Y. Enhanced lightning strike protection of carbon fiber composites using expanded foils with anisotropic electrical conductivity. Compos. Part A Appl. Sci. Manuf. 2019, 117, 211-218. [CrossRef]

8. Kawakami, H.; Feraboli, P. Lightning strike damage resistance and tolerance of scarf-repaired mesh-protected carbon fiber composites. Compos. Part A Appl. Sci. Manuf. 2011, 42, 1247-1262. [CrossRef]

9. Yokoyama, S.; Honjo, N.; Yasuda, Y.; Yamamoto, K. Causes of wind turbine blade damages due to lightning and future research target to get better protection measures. In Proceedings of the 2014 International Conference on Lightning Protection, Shanghai, China, 11-18 October 2014; pp. 823-830.

10. Yokoyama, S. Lightning protection of wind turbine blades. Electr. Power Syst. Res. 2013, 94, 3-9. [CrossRef]

11. Yamashita, S.; Hirano, Y.; Sonehara, T. Residual mechanical properties of carbon fibre reinforced thermoplastics with thin-ply prepreg after simulated lightning strike. Compos. Part A Appl. Sci. Manuf. 2017, 101, 185-194. [CrossRef]

12. Wang, F.S. Experimental and numerical study on residual strength of aircraft carbon/epoxy composite after lightning strike. Aerosp. Sci. Technol. 2018, 75, 304-314. [CrossRef]

13. Garolera, A.C.; Madsen, S.F.; Nissim, M.; Myers, J.D.; Holboell, J. Lightning damage to wind turbine blades from wind farms in the U.S. IEEE Trans. Power Deliv. 2016, 31, 1043-1049. [CrossRef]

14. Hirano, Y.; Katsumata, S.; Iwahori, Y.; Todoroki, A. Artificial lightning testing on graphite/epoxy composite laminate. Compos. Part A Appl. Sci. Manuf. 2010, 41, 1461-1470. [CrossRef]

15. Dong, Q.; Guo, Y.; Sun, X.; Jia, Y. Coupled electrical-thermal-pyrolytic analysis of carbon fiber/epoxy composites subjected to lightning strike. Polymer 2015, 56, 385-394. [CrossRef]

16. Fu, K.; Ye, L.; Zhong, Z. Modelling of lightning strike damage to CFRP composites with an advanced protection system. Part I: Thermal-electrical transition. Compos. Struct. 2017, 165, 83-90. [CrossRef]

17. Yao, X.; Guo, C.; Sun, J.; Chen, J. Damage simulation and experiment of carbon fiber composites subjected to lightning current. High Volt. Technol. 2017, 43, 1400-1408.

18. Zhang, Y.; Wen, X.; Wang, J.; Deng, Y.; Lan, L.; Wang, Y. Arifical lightning testing on wind turbine: Epoxy composite laminate. J. Wuhan Univ. (Eng. Ed.) 2019, 52, 264-269.

19. Guo, Z.; Li, Q.; Yu, W.; Arif, W.; Ma, Y.; Siew, W.H. Experimental study on lightning attachment manner to rotation wind turbine blade. In Proceedings of the 2018 34th International Conference on Lightning Protection, Rzeszow, Poland, 2-7 September 2018.

20. ASTM D7137_D7137M-07. Standard Test Method for Compressive Residual Strength Properties of Damaged Polymer Matrix Composite Plates; American Society for Testing and Materials (ASTM): West Conshohocken, PA, USA, 2007. 
21. Abdelal, G.; Murphy, A. Nonlinear numerical modelling of lightning strike effect on composite panels with temperature dependent material properties. Compos. Struct. 2014, 109, 268-278. [CrossRef]

22. Wang, Y.; Zhupanska, O.I. Modeling of thermal response and ablation in laminated glass fiber reinforced polymer matrix composites due to lightning strike. Appl. Math. Model. 2018, 53, 118-131. [CrossRef]

23. Wang, Y.; Zhupanska, O.I. Lightning strike thermal damage model for glass fiber reinforced polymer matrix composites and its application to wind turbine blades. Compos. Struct. 2015, 132, 1182-1191. [CrossRef]

24. Fu, K.; Ye, L. Modelling of Lightning-induced Dynamic Response and Mechanical Damage in CFRP Composite Laminates with Protection. Compos. Struct. 2019, 218, 162-173. [CrossRef] 